\title{
Tres modelos de transición democrática ${ }^{2}$
}

\section{Introducción}

unque en los tiempos reciente han proliferado númerosos estudios sobre
el proceso de transición a la democracia en El Salvador, podemos decir
sin ningún asomo de duda que muy pocos de ellos han adoptado rigurosa, metodológica y creativamente los criterios básicos de análisis e interpretación ofrecidos por la, relativamente reciente, rama de la ciencia política empírica denominada política comparada. La importancia de tal énfoque de investigación radica en el esfuerzo por interpretar el cambio político - sobre todo en las sociedades del así llamado tercer mundo- desde criterios uniformes y lo más cerca posible de la objetividad científica. Tales criterios, asimismo, permiten, respetando las particularidades históricas de cada caso, extraer aquellos elementos y lecciones comunes explicativos de la viabilidad o inviabilidad de la vigencia de los regímenes democráticos.

Bajo este horizonte, por tanto, el presente trabajo tiene como propósito contribuir al esclarecimiento y a la determinación específica del tipo de transición e instauración experimentado por el régimen político salvadoreño en el período comprendido entre 1992 hasta 1995. Como ya hemos adelantado en otro lugar, la transición hacia la democracia en El Salvador posee un conjunto de características propias que permiten tipificarla como una transición de "baja intensidad"3. Ahora avanzamos en esta misma línea de interpretación argumentando que los patrones de comportamiento que se pueden descubrir al estudiar el proceso de cambio político en El Salvador en los años recientes permiten construir un modelo explicativo del mismo. Un modelo que, por lo demás, compartiría razgos comunes de otros modelos de cambio político elarados a partir del estudio de experiencias previas de transición a la democracia desarrolladas en sociedades nacionales tan disimiles como las de la Europa mediterránea en los años setentas y las Sudamericanas en los años ochentas.

De esta manera, el presente artículo se divide en tres partes: En la primera, 
se ofrece un esquema general de interpretación de los procesos de cambio político a partir de la explicación del contenido de algunas de las categorías básicas contruidas para tal fin. En la segunda, se construyen dos modelos de cambio político los cuales serían de naturaleza fundamentalmente opuesta y que corresponderían a procesos de transición del autoritarismo a la democracia y desarrollados, primero, en la Europa mediteránea y, posteriormente, en América Latina. Finalmente, en la tercera parte se concluye con un breve esbozo de lo que sería un tercer modelo de cambio político. Un modelo más apropiado, a nuestro juicio, para comprender los dinamismos de transformación sociopolítica en Centroamerica en los años noventa.

\section{La teoría de la transición democrática (Algunas definiciones preliminares)}

El objetivo de este apartado consiste en elaborar un breve resumen teórico sobre las diversas explicaciones que en general buscan dar cuenta del proceso de cambio político en las actuales sociedades modernas. Ello cumple con el propósito básico de permitir aclarar los presupuestos y referentes teóricos que orientan y dirigen las presentes reflexiones. Como sabemos, existe un consenso unánime en el seno de la comunidad politológica en virtud del cual se acepta que el estudio del cambio y continuidad de los regímenes políticos constituye un tema de central interés de la rama de la ciencia política denominada política compara$\mathrm{da}^{4}$. Esa literatura especializada permite un análisis riguroso y sistemático de los factores y condiciones que favorecen o retardan el cambio político, las fases y modalidades de la transición, la dinámica de tales procesos y, finalmente, el papel desempeñado por los diversos actores políticos involucrados5. De ahí, entonces, que se justifique nuestra adopción de la política comparada como referente general de desarrollo y nos apoye en la búsqueda de rasgos comunes al examinar las transiciones políticas del autoritarismo a la democracia, en especial aquellas ocurridas en Sudamérica y en la Europa Mediterránea.

En suma, nuestras reflexiones tienen como preocupaciones generales todos los cuestionamientos que surgen al calor del estudio de las transiciones del autoritarismo a la democracia. Por ello, nuestro esfuerzo analítico habrá cumplido sus objetivos fundamentales sí a lo largo de la presente investigación conseguimos introducir algún tipo de iluminación teórica a los cuestionamientos que surgen a la hora de reflexionar sobre el amplio problema del cambio político. Es decir, ¿por qué y cómo se transita de un régimen autoritario a uno democrático?, ¿qué modalidades de transición política pueden individualizarse?, ¿que tipo de modificaciones institucionales exige o produce un proceso político de tal naturaleza?, ¿cuál es la dinámica propia de un proceso de transición democrática?, ¿qué fases de desarrollo pueden identificarse dentro del mismo?, ¿cuándo empieza y cuándo concluye?, ¿cuáles son los factores que indican que una transición hacia la democracia ha sido completamente exitosa?, etc. Problemas que, 
por lo demás, ayudaran a explicar más adelante, asumiendo las debidas precauciones, las particularidades de la marcha del proceso sociohistórico de El Salvador en los últimos años.

El cambio político ha sido y es, naturalmente, un fenómeno frecuente y relevante que afecta en un momento u otro a todas las naciones y sistemas políticos del orbe. Por ello, el cambio repercute -constructivamente o fatalmente- en el destino de las naciones y los pueblos. Ese inevitable cambio, por lo demás, se vive con una intensidad gradual. A veces se manifiesta a través de claras rupturas. En otras ocasiones, en cambio, es paulatino y difícilmente perceptible. Debido a esa universalidad, diversidad y, en definitiva, complejidad del fenómeno en cuestión es necesario adoptar algunas definiciones mínimas. Ellas nos facilitarán entender y delimitar de una adecuada manera la naturaleza, profundidad, dinámica, etc., de dicho proceso. $Y$ es que, justamente, algunas de las semejanzas relevantes claramente perceptibles en distintos procesos de cambio político estudiados han sido agrupadas alrededor de un pequeño grupo de categorías tales como: cambio político —es decir, que se entiende en rigor por dicho concepto-, crisis de régimen, liberalización política y transición democrática. Ellas son, en efecto, categorías y/o conceptos centrales que expresan en su manifestación esencial el fenómeno que nos ocupa y alrededor de los que giran otros conceptos y procesos secundarios entre los que se encuentran, solo para mencionar los más relevantes, los de crisis de legitimidad, pérdida de eficacia decisional, movilización social conflictiva, pluralismo polarizado, institucionalización, etc. 6 Por lo demás, los presupuestos teórico-metodológicos fundamentales en los que afincamos nuestra investigación (y su perspectiva de estudio) son, en este sentido, los siguientes:

a) Todo proceso político se configura y dinamiza a partir de la existencia de un conjunto de actores sociales y políticos -individuales y colectivos, institucionales o no- vinculados entre sí a partir del interés contrapuesto de mantener o transformar el régimen político del cual forman parte. Estos actores persiguen sus objetivos de permanencia o transformación del régimen sobredeterminados por las características particulares que articulan estructuralmente a la sociedad de la que forman parte (conflicto reales y latentes). Estos actores disponen también en su accionar de un conjunto de opciones posibles, amplias o limitadas dependiendo de las circunstancias particulares, las que en definitiva aumentan o disminuyen las probabilidades de éxito de su comportamiento político?.

b) Todo régimen político es dinámico por sí mismo. Ello significa que -en cuanto tal - cualquier régimen se encuentra sujeto a procesos continuos de cambio y adaptación. Los resultados de esos dinamismos son inevitablemente inciertos de modo que, por ejemplo, para el caso de un régimen autoritario, el cambio en dirección democrática durante un proceso de transición es 
solamente una de los posibles desenlaces de su transformación.

\subsection{Cambio político}

Una vez formuladas las necesarias y básicas aclaraciones previas pasamos, pues, a la definición de las categorías mencionadas. Comenzamos, naturalmente, con la definición de cambio político. Este consiste o corresponde fundamentalmente a aquellas transformaciones empíricamente perceptibles que acontecen en el interior de un particular régimen político y/o en sus componentes los cuales, como sabemos, son aquel conjunto de valores, normas y estructuras de autoridad o instituciones políticas que lo configuran8. En realidad, la modificación sufridas por estos componentes son las que nos permiten evaluar el "qué", el "cuánto" y el "cómo" de un determinado cambio político. Se vuelve necesario, en consecuencia, precisar mejor las naturaleza particular de estos componentes de un régimen.

Los valores, obviamente, poseen una naturaleza axiológica. Ellos, en consecuencia, se expresan de diversas maneras a través de las creencias, los principios, las ideologías vigentes en la comunidad política. Tales valores pueden pertenecer tanto a los grupos dominantes como a los subalternos en competición en el seno mismo de la comunidad política. Las normas, por su parte, involucran al conjunto de reglas formales que rigen el ordenamiento institucional existente y que se expresan tanto en las cartas constitucionales como en la reglamentación secundaria. Las estructuras de autoridad, finalmente, comprenden desde las instituciones que canalizan la actividad y autoridad del Estado hasta estructuras intermedias como los partidos políticos o sindicatos u otras organizaciones de carácter variado en virtud de las cuales se manifiestan los diversos intereses y conflictos de la comunidad política.

Ahora bien, dependiendo de las características específicas de estos componentes un régimen político puede ser democrático o no democrático. Además, la etapa de evolución política en que se encuentran tales componentes influyen decisivamente en la determinación del tipo de democracia o no democracia vigente; esto es, de los distintos tipos de autoritarismo posibles. De aquí que para comprender un determinado proceso de cambio político deba recurrirse en su interpretación a la utilización de escalas y tipologías existentes —productos de un necesario proceso de abstracción analítica- para establecer, por ejemplo, el tipo de autoritarismo que da paso a una forma particular de democracia o hacia otra forma de afirmar la dominación autoritaria9. Leonardo Morlino ha desarrollado, en este sentido, un interesante esfuerzo de delimitación de los tipos de cambio político en dirección democrática posibles a partir de los tipos de regímenes autoritarios existentes 10 . Nosotros en el estudio presente, como ya hemos indicado, nos limitaremos a describir como un régimen autoritario -o alguno de sus subtipos - puede evolucionar hacia un régimen democrático. Ello nos lleva 
al típico fenómeno de la crisis de régimen, el segundo concepto que queremos desarrollar.

\subsection{Crisis de régimen}

Una crisis de régimen es aquella situación producida a partir de la aparición de disfunciones e inestabilidades al interior del régimen mismo. Como mencionamos, el dinamismo interno de un régimen consiste, ante todo, en la búsqueda de un equilibrio sumamente difícil de alcanzar y sostener el cual, además, se encuentra permanentemente puesto a prueba. Ello en virtud de que todo proceso político puede reducirse, en definitiva, al establecimiento de demandas de la comunidad política y de respuesta del aparato estatal11. La aparente simplicidad de dicho esquema, sin embargo, no oculta ni obvia la presencia de múltiples cleavages (fracturas) existentes en la sociedad civil y que se transfieren a las estructuras políticas a través de los diversos actores incorporados al régimen político. De hecho, por medio de las respuestas en cuestión, las estructuras políticas deben poseer la capacidad de conciliar esa multiplicidad de intereses y fracturas sociales expresados en las demandas. Cuando la conciliación fracasa y acentúa las fracturas existentes y/o abre nuevas es cuando se rompe el equilibrio sistémico del régimen. Por ello, las crisis de régimen surgen a partir de la "inexistencia de equilibrio entre demandas políticas, apoyos, procesos decisionales y outputs o respuestas a nivel de la relación estructuras de autoridad-comunidad política" 12 , poniéndose, por tanto, en peligro la estabilidad y persistencia del régimen.

Debe destacarse que una de las consecuencia principales en la perdida del equilibrio relativo del régimen se expresa a través de la fractura de la coalición o debilitamiento de la coalición sostenedora de dicho régimen. En efecto, es en el seno de la coalición dominante donde las crisis políticas se manifiestan con particular agudeza. Este hecho adquiere de por sí una importancia de primer orden sobre todo en el caso de crisis políticas que se suscitan al interior de regímenes autoritarios debido a que la fuerza de los mismos se encuentra afirmada, precisamente, en la solidez de la coalición dominante. Y es que en el seno de éstas, al igual que en el seno de la sociedad en su conjunto, existen conflictos y tensiones así como también acuerdos y estrategias básicas entre sus diversos actores 13. Las crisis políticas pueden ser $-\mathrm{y}$ en realidad, frecuentemente lo son-, la primordial fuente de cambio político.

Cabe destacar, asimismo, que la lógica general del o los procesos de cambio político obedece a un doble movimiento. Por una parte, a la aparición de estas fisuras y disensiones significativas en el seno de la coalición dominante que acabamos de mencionar. Por otra parte, el cambio político es también generado desde el interior de las diversas fuerzas de oposición en virtud de su fortalecimiento y consolidación. En efecto, cuando éstas alcanzan mayor penetración, 
reconocimiento social -incrementando sus recursos e influencia políticas- y unidad organizativa interna se encuentran en condiciones de alterar, o al menos de intentarlo seriamenente, la correlación de fuerzas que mantiene unificado y estable al régimen. Es decir, cuando un frente opositor crece y se fortalece, ello suele suponer incluso la incorporación dentro de sí mismo de actores políticos provenientes de la propia coalición dominante que se encuentra en proceso de crisis y división interna. Ello se traduce, por ejemplo, dentro del comportamiento del sistema de partidos en el correspondiente avance electoral de la oposición y el subsecuente replegamiento electoral del partido gubernamental (o que aglutina y representa a la coalición dominante). La coincidencia oportuna, en consecuencia, de ambos factores - división de la coalición dominante y la emergencia de una oposición con clara opción de gobierno- son los que dan paso a un proceso de transformación de un determinado régimen político.

Las crisis políticas, más allá de las características y particularidades expresadas en el desarrollo de las mismas, pueden tener solamente dos tipos fundamentales de desenlace. Un cambio de régimen o una reconsolidación y reafirmación del régimen sometido a la presión transformadoral4. En el primer caso, esto es, cuando el régimen sufre transformaciones esenciales - como ya dijimos al nivel de los valores, normas y las estructuras de autoridad- nos encontramos, en rigor, frente a un proceso de transición política. En el segundo caso, únicamente estamos frente a una crisis política de pequeñas proporciones.

\subsection{Transición política}

La transición política es, pues, en términos generales el paso de un régimen a otro. En cuanto proceso, sin embargo, suele caracterizarse por su incertidumbre y ambigüedad. Es decir, es un proceso al que sólo post festum se puede precisar su intensidad, profundidad y gradualidad en el cambio de régimen. Además, las fronteras que demarcan el inicio y el final del proceso suelen ser, igualmente, poco definidas y claras ya que normalmente quedan constituidas después de la culminación de una situación de confrontación entre grupos que aspiran al control del poder. De ahí que la transición política puede definirse, entonces, como aquel proceso a través del cual actores, instituciones, posiciones de poder y reglas del juego dejan de corresponder a la lógica del régimen anterior sin definirse del todo en una lógica distinta15. La transición justamente termina cuando la lógica emergente queda inequívocamente afirmada. Por lo demás, aquella situación en donde el cambio político se produce con extrema gradualidad, esto es a pequeños pasos, y ampliamente dilatado en el tiempo no puede ser considerado un cambio fundamental y, en consecuencia, no supone como ya hemos indicado un proceso de transición política alguna.

Un proceso de transición política puede desencadenar y concluir, por otra parte, en un espectro intermedio de posibilidades. El cambio político puede ad- 
quirir, por ejemplo, la figura dè una "quiebra democrática" que deviene en autoritarismo o, por el contrario, el desmoronamiento de un régimen autoritario que da paso a uno democrático. Por supuesto, también puede darse el fenómeno expresado en la transformación de un tipo de autoritarismo a otro. En este caso, las posibilidades de cambio se amplian relativamente ya que los distintos autoritarismos ( $\mathrm{y}$ en general los regímenes no democráticos) se distinguen, como sabemos, por el grado de pluralismo político que toleran, el grado de la participación real de la población y el grado de ideologización alcanzado al interior del mismo.

Ahora bien, los distintos tipo de transición existentes pueden distinguirse no sólo por la profundidad de la transformación experimentada. Es decir, por cuanto cambia el régimen en transición, sino también por el modo como cambia ese determinado régimen. Para medir este segundo aspecto del proceso de cambio político existen algunos criterios que permiten uniformizar el análisis del mismo. "En referencia al modo, —nos dice Leonardo Morlino- las dimensiones relevantes en la transición de régimen son cuatro: a) continuo/discontinuo; b) acelerado/lento; c) pacífico/violento; d) interno/externo. Los cuatro aspectos, como se verá, pueden superponerse o incrustarse según cada caso" 16 .

De tal suerte, tenemos que, en primer, lugar el cambio político puede diferenciarse por la gradualidad del mismo. La transición puede ser en este caso continua o discontinua. Es continua cuando el cambio se da a través de una adaptación gradual e incesante frente a los condicionamientos interno o externos que presionan hacia la modificación de los componentes del régimen. Cuando ese proceso supera cierto umbral de transformación puede decirse que la transición se vuelve un hecho consumado. La transición es discontinua, en contrapartida, cuando el cambio se produce de una forma claramente abrupta de modo que se rompe con las normas ordinariamente establecidas por un régimen para regular esa inevitable y constante presión hacia la adaptación de las circunstancias cambiantes del entorno. Los regímenes autoritarios, en efecto, suelen ser más propensos a este tipo de transición discontinua pues, por su propia naturaleza, suelen ser sumamente rígidos y no poseen normas internas de adaptación y cambio 17.

El proceso de transición política puede darse, en segundo lugar, con una intensidad y duración diversa; es decir, el paso de un régimen a otro puede ser rápido o lento. La velocidad depende, como cualquier otra de las modalidades del proceso de transición, de una amplia gama de distintos factores involucrados en el proceso de cambio. Cabe destacar que la mayoría de estos factores dependen, naturalmente, del grado de desarrollo socio-económico y político del régimen mismo.

La tercera dimensión de los procesos de transición tiene que ver con el grado de coerción manifestado en su desarrollo. Todo proceso de cambio lleva, como 
podemos suponer, implícito algún tipo de uso de la violencia. La presencia o ausencia de la violencia no constituye en sí misma la condición determinante del cambio de régimen. Aunque la mayoría de los tipos de forma de violencia acompañados de otros factores sí constituyen la formula que lleva a la caída de un régimen y a la emergencia de otro. La violencia, por lo demás, puede, dependiendo de su extensión e intensidad, manifestarse, por ejemplo, a través de diversas formas como son: los tumultos, las protestas populares -especialmente cuando van acompañadas de una respuesta represiva de las fuerzas gubernamentales-, las conspiraciones y golpes palaciegos hasta llegar a la guerra civil y las muy distintas manifestaciones y expresiones del terrorismo organizado. El recurso a la violencia, en definitiva, es una de las constantes más características de los procesos de transición. Su eficacia es relativa. Grados extremos de violencia como los desencadenados en las guerras civiles normalmente llevan, más allá de que actor o coalición de actores resulte triunfante, a un cambio de régimen aunque también se da el caso de que puede lograrse este mismo objetivo con uso mínimo de la violencia. Por otra parte, golpes palaciegos no siempre son expresión de cambios de régimen sino únicamente cambios de gobierno. Lo que sí parece ser una constante es que "el cambio fundamental es más profundo y, por tanto, el nuevo régimen es menos parecido al anterior cuando más intenso, extenso y prolongado haya sido el empleo de la violencia"18.

Cuando se habla del origen interno o externo de una transición —esto es la cuarta modalidad del cambio político- se hace referencia con ello a la localización de los actores o factores que desencadenan el proceso de cambio. Esto significa que el cambio interno será aquel proveniente de modificaciones ocurridas dentro del sistema socioeconómico y político del régimen que motivan la movilización usualmente conflictiva de los actores políticos del mismo. El cambio externo, por su parte, es aquel que resulta de la influencia dentro del régimen de acontecimientos o la actuación de actores foráneos que rompen o modifican el equilibrio propio del régimen. Este es el caso, por ejemplo, de una crisis económica global que afecte de forma particularmente negativa a un régimen o la intervención de potencias extranjeras en la configuración de una salida especifica a una situación de crisis de régimen. Dicho lo anterior es oportuno ofrecer la concepcion de transicion politica a la que nos adscribimos:

"Por transición política entendemos con G. O’Donnell y P. Schmitter: "el intervalo entre un régimen político y otro, entendiendo por régimen el conjunto de patrones, explícitos o no, que determinan las formas y canales de acceso a las principales posiciones gubernamentales, las características de los actores que son admitidos, y excluidos de ese acceso y los recursos y estrategias que pueden usarse para tener acceso". En este sentido, La transición de un régimen autoritario a uno democrático supone el cambio de un conjunto de arreglos institucionales y prácticas políticas definidas y controladas discrecionalmente por la élite en el poder, por otro acuerdo en el que la 
definición y el funcionamiento de las estructuras y prácticas políticas se someten a la discusión, están garantizadas por la constitución y están respaldadas por la participación ciudadana. Los momentos de la transición están definidos por el cuestionamiento de los arreglos institucionales y las prácticas políticas; esto es, por la ausencia de consenso sobre ellos y la lucha por la definición y restablecimiento de unos nuevos" 19.

\subsection{Liberalización política}

Nos queda aún uno de los conceptos fundamentales para el estudio del cambio político que se encuentra sumamente ligado con las transiciones del autoritarismo a la democracia al menos, como veremos a continuación, con una de las maneras más frecuentes - y quizás hábiles también- que encuentran los lideres autoritarios para contener y/o neutralizar las presiones hacia la democratización del régimen que controlan. Este concepto es, justamente, el de liberalización política y con él se intenta comprender y conceptualizar aquellos procesos de apertura gradual y controlada producida en el interior de un régimen autoritario por la propia élite en el poder. La liberalización política, por tanto, no es otra cosa más que la manifestación de una respuesta institucional que persigue prevenir el desencadenamiento de una crisis de régimen producto de la formación, afirmación y radicalización de las fuerzas políticas de oposición y de su probable confrontación con el régimen autoritario. La lógica fundamental de cualquier proceso de liberalización política consiste, como decimos, en encauzar el proceso de demandas y protestas de la oposición — cuando estas adquieren dimensiones amenazantes contra la estabilidad del régimen- mediante la concesión de los respectivos espacios de expresión y participación política20. Obviamente, tales espacios se encuentran limitados por la misma supervivencia del régimen $\mathrm{y}$, de hecho, la élite que impulsa tal apertura la maneja con toda discresionalidad dado que el objetivo de ella es justamente el de afimar y fortalecer la continuidad del régimen en cuestión. La liberalización constituye, entonces, una respuesta institucional hacia la aparición de potenciales conflictos deslegitimadores $y / o$ desestabilizadores del régimen puestos en evidencia a partir de un sensible aumento de la movilización social.

Todo proceso de liberalización política supone, pues, la afirmación y vigencia de un parcial y relativo respeto por los derechos civiles así como de la correspondiente ampliación del marco constitucional sobre el cual se legítima el régimen. Aquí es donde se encuentra, justamente, el ámbito de eficacia de la neutralización institucional del potencial conflicto. Ello, naturalmente, estimula de una manera u otra la emergencia y participación de la oposición -sobre todo de la oposición leal o oposición subordinada a la existencia misma del régimen- aunque una de las limitaciones fundamentales del proceso de liberalización consiste en que dicha oposición se encuentra por definición excluida de la posibilidad de acceder al poder. La tolerancia a su existencia encuentra su senti- 
do, precisamente, en el establecimiento de una situación de semicompetencia política en donde la existencia de la oposición confiere legitimidad al grupo hegemónico sin poner en tela de juicio su dominio y control del ejercicio del poder.

Por todo lo dicho, se impone entonces distinguir claramente entre los procesos de liberalización y de transición democrática. La democratización, en rigor, es un proceso que conduce de una situación autoritaria a una democracia pluralista, mientras que la liberalización indica sólo una apertura que no finaliza necesariamente con aquel resultado, sino que puede ser orientada a restablecer la situación anterior 21 . La liberalización y la democratización son, en este sentido, dos procesos diversos, alternativos y, eventualmente, el segundo es sucesivo del primero. Ello se da, naturalmente, cuando la liberalización se ve, después de todo, desbordada por la presión o los impetus democratizadores que eliminan el aspecto estabilizador de la liberalización y profundizan, en cambio, las fisuras al interior de la coalición dominante e incrementan la fuerza de la oposición.

"La liberalización se caracteriza por la concesión de algunos derechos políticos y civiles, pero en una línea de organización controlada de la sociedad civil. Su implementación responde a las necesidades de un régimen autoritario de aumentar o conservar las bases de su sustento social o legitimidad, sin "civilizarlo" completamente. La democratización, por su parte, connota una ampliación completa y un reconocimiento real de los derechos civiles y políticos, creando las condiciones para el pluralismo y la participación, garantizados previo acuerdo de las distintas fuerzas políticas actuantes" 22 .

Desde la perspectiva de la democracia política, un régimen que pueda ser calificado como tal es aquel configurado a partir de normas destinadas a garantizar efectivamente la protección de los derechos políticos y civiles de los miembros de la comunidad política. Es decir, en un régimen democrático, por ejemplo, poseen plena vigencia los derechos de reunión y asociación, las libertades básicas tales como la libertad de pensamiento, palabra y prensa y, el derecho de sufragio activo. Otros rasgos clásicos del ordenamiento democrático serían, asimismo, el predominio del estado de derecho y la relativa independencia de los poderes judicial y legislativo junto al otorgamiento de garantías destinadas a fomentar el respeto real a los derechos humanos. Robert Dahl, el autor que mejor ha observado empíricamente y teorizado sobre los contenidos a partir de los cuales se construyen las democracias (o Poliarquias como el prefiere denominarlas), sostiene con mayor precisión que un régimen democrático se juzga en base a dos dimensiones, a saber; la existencia de competencia política o la posibilidad de oposición y la extensión de la participación.

La primera dimensión viene dada por el "grado en que las instituciones están abiertamente disponibles, destinadas públicamente y garantizadas, al menos para algunos miembros del sistema político que deseen contestar la actuación guber- 
nativa"23. La segunda viene dada por la "proporción de población que puede participar, sobre bases paritarias, en el control del gobierno y que puede contestar la actuación de éste, es decir por la proporción de aquellos que tienen derecho a participar en un sistema de competencia"24. Para Dahl, pues, toda democracia auténtica se caracteriza por poner el mínimo de restricciones a la expresión, organización y representación de opciones políticas y a las oportunidades de que disponen los oponentes del gobierno para desarrollar dicha actividad. Bajo este esquema, naturalmente, la participación electoral ocupa un lugar central. Esto es, la realización de comicios transparentes, limpios y equitativos resulta crucial para medir la eficacia y autenticidad de los procedimientos democráticos 25 .

En suma, un régimen democrático será entendido básicamente como un conjunto de reglas explícitas y prefijadas para la resolución pacífica de los conflictos. Los arreglos políticos, por tanto, emergen del resultado de compromisos, cuyo producto sustancial permanece relativamente incierto. Ambos aspectos -resolución pacífica de los conflictos e incertidumbre final- no pueden faltar sobre todo en los procesos de transición de regímenes autoritarios a democráticos. Para Adam Przeworski, en efecto, la transición a la democracia puede interpretarse como un proceso de institucionalización de la incertidumbre; es decir, un proceso en el que todos los intereses son sometidos a la incertidumbre. De ahí que en una democracia ningún grupo puede intervenir con una capacidad de control hegemónico cuando los resultados de los conflictos perjudican sus intereses. Es precisamente este acto de enajenación del control de los resultados de los conflictos y su institucionalización el que constituye el paso decisivo hacia la democracia26.

En su concepción mínima, pues, la democracia es un conjunto básico de procedimientos que crean espacios para la participación política y, al mismo tiempo, garantizan su ejercicio. El respeto a estos procedimientos da lugar a que los conflictos puedan ser resueltos de una manera pacífica -aunque no siempre satisfactoria para todos. Por lo demás, estos procedimientos son creados, reproducidos y transmitidos por las instituciones que configuran a un determinado régimen político. De ahí que por institucionalización se entienda, justamente, a aquel proceso de formación y reforzamiento de las normas y estructuras que hacen funcionalmente efectivo a un régimen. En las instituciones recaen, de hecho, las funciones de mantener el orden, resolver los litigios, elegir los líderes y promover una forma de convivencia estable entre grupos sociales enfrentados27. Por ello, autores como Leonardo Morlino suelen identificar la etapa de consolidación de un régimen democrático con este proceso de creación de procedimientos e instituciones que lo hacen - como decimos- viable y efectivo ${ }^{28}$. Recordemos que una vez instaurado un determinado régimen democrático se le presenta al mismo de forma inmediata el desafío de garantizar aquellas condiciones necesarias e imprescindibles para su regular funcionamiento. En esto, 
precisamente, radica o consiste la etapa de la consolidación de la democracia. En cuanto tal, pues, es una etapa que requiere de la institucionalización de las normas y estructuras características del ordenamiento democrático, así cómo también de la extensión de su legitimidad. A diferencia de la instauración democrática, la consolidación es un proceso prolongado sin una duración cabalmente determinada.

Hasta acá, entonces, el desarrollo de los principales conceptos y categorías que la ciencia política contemporánea utiliza para describir o argumentar sobre la naturaleza y dinámica de los fenómenos de cambio o continuidad de y en los sistemas y regímenes políticos. A continuación desarrollaremos en sucesivos apartados los dos modelos de cambio político más conocidos en el campo de la política comparada. Se trata de aquellos modelos de cambio político construidos por diversos y connotados representantes de la ciencia política empírica para explicar los procesos de transición del autoritarismo a la democracia experimentados en las naciones de la Europa mediterránea a lo largo de la década de los setenta y en Sur América durante la década de los ochenta29. En este sentido, cabe realizar las acotaciones siguientes:

En primer lugar, como ya hemos adelantado, el objetivo de la presente investigación intenta mostrar como los procesos de cambio político sufridos por las sociedades centroamericanas a lo largo de la década de los ochentas y principios de los noventa poseen un conjunto de características comunes que los diferencian de otros tipos de procesos de cambio político en distintas regiones del mundo que los han antecedido. Tales características comunes configurarían, a nuestro juicio, un modelo explicativo propio tal y como pretendemos demostrar a lo largo de la presente investigación. La referencia a los casos mencionados en la Europa mediterránea y Sud América son realizadas, por tanto, a título de procedimiento metodológico de control 30 . Es decir, asumiendo que los procesos de cambio político poseen por su propia naturaleza cierta realidad homogénea que facilita establecer ciertas regularidades comunes. Regularidades que son, después de todo, sumamente frágiles y aproximativas. Ellas no pretenden, pues, tener el estatuto de una ley científica apodíctica e inexorable.

En segundo lugar, la anterior objeción significa que el valor de los modelos de cambio político existente es relativo y que asumimos conscientemente esa eventualidad. Ello debido a que el desarrollo y el éxito de un proceso de democratización varía considerablemente y se muestra dependiente tanto de factores históricos y estructurales de largo plazo 31 como también de factores coyunturales de corto plazo"32. La comparación con España -uno de los casos más estudiados y a partir del cual se ha construido el modelo de transición pactada a la democracia-- permite verificar lo diferentes que han sido las condiciones y evoluciones en otros procesos de democratización.

Una vez hechas ambas aclaraciones, también queremos sostener, sin que ello 
resulte inevitablemente contradictorio, que, de manera general, se pueden identificar factores comunes o semejantes tanto en las transiciones a la democracia desarrolladas en los países mediterraneos durante los años setentas como también por las ocurridas en las naciones Sudamericanas a lo largo de los años ochentas. Tales transiciones, pues, obedecen a un patron similar -en términos del curso seguido, el grado de similitud manifestada en el desempeño de los principales actores sociopolíticos, los nuevos marcos constitucionales establecidos, etcétera- si bien con un énfasis opuesto en sus cáracteres constitutivos. Es decir, dicho de una manera más específica, las transiciones hacia la democracia en los países de la Europa Mediterranea tuvieron un carácter continuo, lento, pacífico e interno. En cambio, las transiciones a la democracia en los países sudamericanos mostraron rasgos fundamentalmente opuestos, lo cual significa que ellas se caracterizaron por ser discontinuas, acelaradas, violentas y externas ${ }^{33}$.

Para comprender nuestra anterior afirmación con mayor claridad, recordemos que una de las mayores diferencias existentes en los procesos de cambio político en cuestión radica en la formulación de un pacto político explícito y normativo producto de la participación de los principales actores políticos involucrados en esos procesos de transición. De esta suerte, en las sociedades de la Europa Mediterránea, en efecto, tal pacto habría regulado la continuidad, pausavidad e intensidad del advenimiento a la democracia, mientras que la falta del mismo explicaría, por su parte, la discontinuidad, celeridad y superficialidad lograda por la instauración democrática en los casos de las sociedades Sudamericanas.

\section{El modelo consensuado}

En La Tercera Ola ${ }^{34}$, Samuel Huntington construye, tomando como variable de base la correlación de fuerzas establecidas en un determinado momento entre el gobierno y la oposición, tres modelos básicos de transición pacífica a la democracia. Dichos modelos se conocen con el nombre de Transformaciones (Transformation), Reemplazos (Replacement) y Traspasos (Transplacement). Brevemente caracterizados, la dinámica de cambio político a la que dan paso se definiría de la siguiente manera 35 :

Las transformaciones ocurren, dice Huntington, cuando las élites en el poder apuestan por la democratización en función de garantizar el control del proceso y el mantenimiento de importantes cuotas de poder. Acá se trata de élites dominadas por sectores "blandos" que buscan prevenir su caída y que, en el fondo, aspiran a mantenerse en el poder de manera legitimada. Los reemplazos, en cambio, poseen una lógica inversa y suponen la existencia de una oposición fuerte y que tiene la capacidad para imponer el cambio político de acuerdo a sus condiciones sometiendo por tanto a las fuerzas y sectores vinculados al gobierno. Finalmente, el traspaso se articula a partir de una situación intermedia en 
donde existe más bien un equilibrio de fuerzas entre el gobierno y la oposición pero que no está claramente definido. Ninguno de los oponentes, entonces, se encuentra seguro de imponerse a su adversario y -al predominar los moderados en ambos bandos- prefieren pactar las condiciones, ritmos y profundidad del proceso de cambio.

\subsection{Un pacto explícito y viable para la transición}

Ahora bien, al estudiar las características propias y el tipo de variables políticas y su desempeño dentro de los distintos procesos de transición democrática ocurridos a lo largo de la década del setenta en las sociedades del sur de Euro$\mathrm{pa}^{36}$ nos encontramos con que tales procesos obedecen o se ajustan muy bien al modelo de "traspaso" propuesto por el profesor Huntington. En general, cuando una transición a la democracia sigue el modelo del "traspaso", las condiciones para su instauración y consolidación suelen ser las idóneas; es decir, las mejores condiciones para establecimiento y vigencia de un régimen democrático. La razón de ello estriba, a nuestro juicio, en la situación de equilibrio existente entre la coalición autoritaria y las diversas fuerzas de la oposición. Se debe a dicha situación, en efecto, que las fuerzas políticas de signo opuesto logran concertar, en el contexto de una situación de crisis política, un pacto o acuerdo que rija los pasos o procedimiento para alcanzar un marco de "normalidad" política37.

Las transiciones a la democracia que han sido guiadas por un acuerdo efectivo suele ser, como ya hemos dicho, más ordenadas, seguras y confiables con relación a su inequívoco desenlace democrático. Y, es que, conducir un proceso de cambio político bajo un acuerdo viable ofrece ventajas nada desdeñables para los contendientes políticos. En primer término, a través del acuerdo se configuran condiciones de competencia real, sobre bases de mayor equidad entre ambas partes, y sobre el presupuesto de que poseen una oportunidad verdadera de ganar el control del gobierno y/o de las estructuras de toma de decisión, si se apegan a las reglas establecidas. En segundo lugar, las partes, a su vez, aceptan la posibilidad de triunfo de su rival, dado que la naturaleza de los pactos o acuerdos de tal naturaleza suelen también conllevar garantía mutuas de respeto a la integridad y existencia, así como de la concesión de espacios legítimos de participación a la o las fuerzas políticas perdedoras. En tercer lugar, para el proceso político en su conjunto, en el caso de las transiciones pactadas, resulta comprobable la disminución de los niveles de discresionalidad, el aumento de los criterios de racionalidad 38 y el apego y respeto a las nuevas reglas y procedimientos (muchos de los cuales alcanzan rango constitucional) de corte democrático.

El denominado acuerdo o pacto de la Moncloa en España constituye, en ésta línea de argumentación, uno de los mejores ejemplos de como conjuntar a todas las fuerzas relevantes de una nación para dar paso a un cambio político de largo 
aliento de forma concertada y satisfactoria para todos 39 . Su objetivo no fue otro, en efecto, que la construcción de un esquema constitucional, producto de una reforma política profunda, iniciada tras la muerte del General Franco y que culmino en 1978 con la aprobación de la Constitución Española vigente40.

Es cierto que para relativizar el beneficio producido por los pactos muchos apelan, con toda razón, a la excepcionalidad de la transición política española. Sin embargo, todas las formulas de transición exitosa conducidas bajo el modelo del "traspaso" ensayaron con acierto estrategias de aperturas políticas pactadas que culminaron en prominentes reformas constitucionales. En el caso de las transiciones de la Europa Mediterránea, España no es una excepción. Italia (1947), Francia (1958), Portugal y Grecia (ambas en 1976) cristalizaron y/o estrenaron sus respectivas reformas constitucionales en el marco del proceso de instauración democrática.

Ahora bien, junto a la existencia de un pacto explícito y viable que regula la transición a la democracia, los procesos de cambio políticos regidos por el modelo del "traspaso", también poseen en común otras variables constitutivas (y favorables a la democratización efectiva) tales como: a) un contexto internacional favorable para la transición a la democracia; b) un rol menor de las fuerzas armadas en la articulación y vigencia del régimen autoritario; c) una sociedad civil fuerte y activa; y, d) una sociedad menos polarizada ideológicamente 41 .

\subsection{La importancia de un contexto internacional favorable}

Una nota francamente paradójica de las transiciones a la democracia suscitadas en los países de la Europa Mediterránea estriba en el hecho de que tanto en la etapa de la instauración como la consolidación democrática los resultados conseguidos por dicho proceso en tales países resultaron ser ejemplares o, por lo menos, satisfactorios. Lo paradójico de ello surge del hecho incontrovertido de que estos países (España, Portugal, Grecia, etc.) habían sufrido una presencia de la dominación autoritaria sumamente prolongada y profunda 42 .

El impacto de esa duración más continuada estriba, por supuesto, en la honda modelación de las estructuras sociales y económicas, de las instituciones civiles y políticas e, incluso, de los valores individuales, pero compartidos por la comunidad, que el estilo de dominación y organización autoritario tuvo ocasión de ejercer. En opinión de Leonardo Morlino, en efecto, "la instauración es tanto más rápida y más probable la consolidación cuando menos tiempo ha durado la persistencia del régimen autoritario"43.

Tal paradoja, pues, adquiere mayor relieve cuando se le contrasta con las transiciones a la democracia de los países del cono sur, las cuales fueron mucho más frágiles y problemáticas a pesar de no haber sufrido la dominación autoritaria por un período de tiempo tan prolongado. Cabe señalar, no obstante, que si 
bien es cierto los autoritarismos sudamericanos resultaron ser fenómenos más bien variados, recientes y episodicos, la experiencia previa de la democracia tampoco muestra que como régimen político ella haya sido en estos mismos países la norma más común y consolidada. Otro aspecto a favor de los autoritarismos de la Europa Mediterránea es el hecho de que bajo su egida dichas naciones sufrieron cambios considerables a distintos niveles. El caso español es una vez más ilustrativo al respecto. El crecimiento y desarrollo económico experimentado bajo los largos años del Franquismo transformaron sustancialmente a la sociedad española haciendo cada vez más necesaria la transición democrática. En este sentido puede decirse que el Franquismo fue víctima de su propio éxito 44 .

Sin embargo, la pregunta esbozada inicialmente sigue, después de todo, en pie. Es decir, si lo dicho anteriormente sobre el impacto de la duración del autoritarismo es cierto "ipor qué, entonces, las liberalizaciones/democratizaciones del Sur de Europa desembocaron en lo que parece ser un punto de partida mejor y más seguro (para la instauración y consolidación democrática)?"45.

Philippe Schmitter responde a tal interrogante afirmando que:

"Una explicación parcial es la de que el contexto internacional en esa parte del mundo y en este momento brinda mayor apoyo a un desenlace de este tipo. Italia primero, y Grecia, Portugal y España más tarde (el caso turco es más ambiguo) han quedado envueltas en una red compleja de instituciones regionales, intercambios comerciales, presiones políticas, vinculaciones partidarias, obligaciones emergentes de tratados, contactos entre ciudadanos y expectativas normativas que recompensan las adecuaciones a la democracia, y castigan que se la trasgreda" 46 .

La posición geoestratégica fue, de acuerdo con tal hipótesis interpretativa, una ventaja a favor de los procesos de democratización en dichas naciones. Por supuesto, las variables externas juegan, a pesar de su relativa importancia, un rol menos determinante que el desempeñado por los actores y las condiciones internas de cada país.

\subsection{El rol marginal de las Fuerzas Armadas}

Todo autoritarismo por definición supone, entre otros factores, el ejercicio de la coacción y violencia en dosis elevadas y al margen de los controles y normas que mantiene a dicha coacción dentro de los límites de lo legítimo. Los militares, a su vez, son los actores encargados de "administrar" tales mecanismos de la coacción y de mantenimiento del orden y de la seguridad. De ahí, entonces, que la institución castrense suela desempeñar (por "vocación" o por "inducción") un rol central en la configuración y vigencia de los autoritarismos. 
Ese rol se articula a partir de dos vertientes47. En primer lugar, desde la configuración de unas precisas relaciones entre civiles y militares que alcanzan como clímax de su expresión negativa la completa subordinación de la esfera de lo civil a lo militar. Es decir, el aparato estatal es copado por miembros de la institución armada quienes lo organizan y manejan de acuerdo a sus principios y concepciones doctrinarias. Se trata, por supuesto, de concepciones, códigos y normas reñidos con los principios democráticos48. En segundo lugar, ese rol también se configura desde la responsabilidad asumida por las Fuerzas Armadas en la ejecución de actos de coacción y represión (oficiales o no, pero de todas formas ilegales y frecuentemente masivos) dirigidos sistemáticamente contra las fuerzas de la oposición y la población civil en su conjunto de una manera más o menos indiscriminada.

Al contrastar, entonces, el grado de influencia y/o determinación ejercida por el estamento militar en las naciones mediterráneas con los países sudamericanos la diferencias son verdaderamente notables. En efecto, en los primeros países el grado de militarización fue sustancialmente bajo de modo que "ni la Italia fascista, ni Portugal en la época de Salazar o aún España en la época de Franco (donde el gobierno a despecho de sus orígenes en una guerra civil y del papel prominente que asignó a los funcionarios militares, fue adaptándose progresivamente a la vida civil durante la larga etapa de la dictadura)—, las tareas más directas y "sucias" fueron cumplidas con una policía política que no estaba formalmente subordinada a los cuadros militares" 49 .

Este rol relativamente modesto y pequeño de las Fuerzas Armadas en la configuración del régimen autoritario (Grecia constituye en este sentido un caso aparte más cercano al modelo del cono sur) y su funcionamiento se transformo en una innegable ventaja para el proceso de transición democrática. En realidad, "quizás de una significación aún mayor que la pauta general de las relaciones entre civiles y militares haya sido la ausencia de una responsabilidad directa en estos países, por parte de las fuerzas armadas como tales, respecto de actos de violencia oficial y no oficial dirigida contra la población civil's0. Dicho de otra manera, la magnitud y la "calidad" de la represión física alcanzaron niveles muy inferiores en las naciones mediterráneas que la evidenciada en los países suramericanos. Adicionalmente, en la mayoría de estos países - aquí España vuelve a ser ejemplar- el recuerdo de tales acciones represivas se habían diluido y/ o atenuado con el transcurso del tiempo. En tales circunstancias, nos dicen Schmitter y O'Donnell, las personas que participaron en forma directa, o bien se retiraron de la vida pública o bien han sido olvidadas, y los dirigentes de los partidos y grupos representativos de las víctimas pueden instar a los actores políticos a "no escarbar en el pasado"'51.

Con todo, una menor responsabilidad de los militares en la formulación y organización de las políticas del régimen autoritario, así como también una me- 
nor responsabilidad en los (siempre brutales) hechos de violación a los Derechos Humanos, no bastan para explicar completamente las mejores condiciones para la instauración y consolidación democrática en las naciones del sur de Europa. Para muchos politólogos e historiadores, en efecto, las sociedades del sur de Europa se caracterizan, especialmente frente a las de América Latina, por poseer sociedades civiles más "elásticas" y "viables" 52.

\subsection{La importancia de una sociedad civil fuerte}

Como sabemos, la sociedad civil es aquel conjunto de actores sociales, económicos y políticos organizados para la defensa y promoción de sus intereses53. Es decir, en su acepción amplia, la sociedad civil estaría integrada por las organizaciones e instituciones más diversas e, incluso, disímiles, a saber: los gremios empresariales, las universidades, los sindicatos y asociaciones cooperativas, etc. Por supuesto, esa concepción tan amplia se restringe al acotar que una de las características básicas de esas organizaciones, para ser tomadas en cuenta como parte de la sociedad civil, es el hecho de que, en sentido estricto, estas organizaciones sociales, en cuanto tal, no aspirarían o detentarían un cuota de poder político. La contrapartida de la sociedad civil sería, en consecuencia, la sociedad política54. Es decir, todas las instancias estatales, partidos políticos (y en el caso de un proceso revolucionario, las organizaciones político-militares).

Por supuesto, una cosa que no hay que perder de vista es que, en la vida real, los individuos se desplazan entre la sociedad civil y la sociedad política -al igual que en la vida real sociedad civil y sociedad política constituyen dos ámbitos interrelacionados entre sí, sólo separables analíticamente-, siendo crucial para determinar su lugar en una y otra, la función desempeñada en cada situación específica. También hay que señalar que si bien las organizaciones de la sociedad civil no aspiran a acceder a una cuota de poder político, ello no quiere decir que con su presencia activa no deban buscar incidir en lo político, particularmente en aquellas instancias responsables de la conducción política de una nación, es decir, en las instancias de la sociedad política.

Recordemos que uno de los aspectos fundamentales que preceden a las etapas de cambio político se expresa a través de un sensible incremento de la movilización política por parte de todas las organizaciones y miembros que constituyen a la sociedad civil. En efecto, la movilización política intensa no es otra cosa que una acelerada elevación de demandas que se constituyen en desafíos políticos visibles (que se pueden medir empíricamente a partir de ciertos parámetros: número de personas que planteen el desafío, intensidad con que se plantea, importancia de la demanda para los grupos sociales políticamente relevantes, etc.) a la coalición dominante. En este sentido las movilizacionés políticas emanadas desde el seno de la sociedad civil contribuyen a acelerar una crisis política o influye en un proceso de cambio de régimen así como en su posterior 
consolidación 55 .

Admitido todo lo anterior, salta a la vista el contrastante nivel de desempeño manifestado por los integrantes de la sociedad civil en los países de la Europa Meridional, por una parte, y en los países de América Latina, por la otra. Es decir, en el caso de los países mediteráneos, la movilización y las presiones desde abajo fueron los factores fundamentalmente conducentes a una apertura del gobierno autoritario, más que la mera aparición previa de conflictos y físuras dentro de la coalición dominante. En cambio, en los países de América Latina, muy probablemente, la situación anteriormente descrita pudo haber sido a la inversa dado de que existen ciertas evidencias históricas que señalarían la posibilidad de que sus respectivas "sociedades civiles" podrían estar diferentemente configuradas y ser diferencialmente viables56. De nuevo con Philippe Schmitter podemos sostener que:

"Según la hipótesis básica, para montar un desafío efectivo y perdurable a la dominación autoritaria, y para que la democracia política se convierta en y siga siendo un modo alternativo de dominación política, un país debe poseer una sociedad civil en la cual existan ciertas identidades comunitarias y grupales con independencia del Estado, y ciertos tipos de unidades autoconstituidas que sean capaces de actuar con autonomía en defensa de sus propios intereses e ideales. Además, estas identidades e intereses no sólo deben estar distribuidos en todo el país; también es necesario que puedan ser concentrados cuando la ocasión lo exige, es decir que deben ser organizados para la acción colectiva coherente. (...) Obviamente, ésta no es una observación demostrable. En todo caso es claro que la transición desde el gobierno autoritario no constituye meramente una cuestión de desarrollo económico o complejidad social"s7.

Un último aspecto estrechamente relacionado con el desempeño de la sociedad civil es la articulación y dinámica del sistema de partidos que la acompañó. En esta dimensión, las sociedades del Sur de Europa se caracterizaron por mostrar un patrón muy homogéneo en el cual los partidos de centro (moderados) se afirmaron y fortalecieron dominando, de tal suerte, a sus rivales más radicalizados de la izquierda y la derecha en el curso de la celebración de comicios fundacionales 58 . Ello fue acompañado, asimismo, de una competencia fundamentalmente centrípeta y una mayor tendencia hacia la estabilización del sistema político en su conjunto, pero particularmente reflejada en la estabilización de la relación entre las instituciones de la sociedad civil y los partidos políticos.

En suma, pues, las naciones europeas habrían manifestado un mayor nivel de "civilidad" lo cual le proporcionaría la existencia más definida de valores individuales, identidades grupales y aspiraciones colectivas, así como mayores índices de autonomía frente a la autoridad estatal (o a la manipulación gubernamental) lo cual habría contribuido de una forma más que eventual con la instauración y 
la consolidación democrática.

El cuadro No. 1 resume de manera sinóptica el modelo de "transición pactada" o de "transición por traspaso" que caracteriza a los países de la Europa del Sur.

\section{Cuadro No. 1}

\section{Europa Mediterránea: Transiciones pactadas}

\begin{tabular}{lll}
\hline Variables & \multicolumn{1}{c}{ Desempeño } \\
\hline Transición & $* \begin{array}{l}\text { Existencia de un pacto político (y a veces } \\
\text { también económico) explí́ito entre } \\
\text { los principales actores sociopolíticos }\end{array}$ \\
\hline Fuerzas Armadas & $* \begin{array}{l}\text { Rol modesto } \\
\text { Menor nivel y/o ausencia de responsabili- } \\
\text { dad en la violencia oficial }\end{array}$ \\
\hline Sociedad Civil & $* \begin{array}{l}\text { Movilizaciones y presiones desde abajo } \\
\text { Predominio de partidos moderados de cen- } \\
\text { tro }\end{array}$ & $\begin{array}{l}\text { Los líderes del cambio provienen del in- } \\
\text { terior del régimen autoritario }\end{array}$ \\
\hline Contexto Internacional & $*$ & Favorable \\
\hline Tipo de régimen & $*$ & $\begin{array}{l}\text { Menor grado de militarización } \\
\text { Autoritarismo y Fascismo }\end{array}$ \\
\hline
\end{tabular}

\section{El modelo conflictivo}

Corresponde ahora dedicar la atención al estudio de aquel conjunto de factores comunes que caracterizan los procesos de transición a la democracia acaecidos en los países Sud Americanos a lo largo de la década de los ochenta. Como ya habíamos adelantado, el modelo de transición política compartido por estas naciones obedece, en la terminología de Huntington, al esquema del "reemplazo" y supone un colapso del régimen político ya que la oposición ha llegado a alcanzar la fuerza necesaria y la capacidad para derrocar a los gobernantes autoritarios.

Argentina es, dentro de este amplio número de países, el caso que mejor se apega a dicho modelo de ruptura conflictiva59. De hecho, si de establecer con- 
trastes se trata, el caso argentino podría representar, sin duda, la antítesis mas fiel del socorrido caso español60. Es decir, en Argentina se produce un colapso de la élite autoritaria producto de sus propias fisuras internas (debido al predominio de los sectores duros) y de la derrota militar sufrida a manos de la armada británica en la aventura ideada por los militares argentinos para recuperar las islas Malvinas. No hay, por tanto, un pacto entre las principales fuerzas políticas que regule los tiempos y los modos de la transición. Se trata de una característica que, naturalmente, posee ventajas y desventajas respecto del tipo y profundidad del proceso de transición desencadenado.

En efecto, en el caso de una transición determinada por el colapso del régimen autoritario lo más seguro es que se produzca una más completa -0 , al menos, menos restringida - transformación en orden a establecer una democracia política61. Desde la perspectiva menos ventajosa, estas transiciones poseen en común su alto nivel de incertidumbre, la cual se ve acentuada por la presencia de fuertes oposiciones desleales y confrontaciones directas e intensas entre los distintos grupos, organizaciones, partidos y facciones e intereses organizados62. La principal razón explicativa del surgimiento de dicha oposición ferozmente desleal estriba en la naturaleza misma de la transición por colapso o "reemplazo" ya que dejan a las clases dominantes (Empresarios, Oligarcas, etc.) e, igualmente, a las Fuerzas Armadas con muy escasa representación en el escenario institucional del proceso de transformación política. De esta suerte, tales grupos y organizaciones, al percibir al proceso de transición como una segura amenaza para sus intereses, utilizan todos sus recursos, que frecuentemente no son pocos, para obstaculizarla.

\subsection{Ausencia de pactos políticos para normar la transición}

La diferencia más destacada, al examinar los procesos de cambio político entre los casos latinoamericanos y la mayoría de los sudeuropeos, consiste, sin duda alguna, en el papel central desempeñado en los primeros por las Fuerzas Armadas. No se trata, por supuesto, de un dato sin importancia. Y, el mismo se vuelve más acentuado si se menciona la mayor heterogeneidad y diversidad propia experimentada por cada uno de los países señalados en el desarrollo de sus respectivos procesos de transición63. Dicho lo anterior, podemos decir que la segunda diferencia más relevante radica, justamente, en la ausencia de pactos o acuerdos políticos explícitos, formales para regular y conducir el proceso de transición 64 .

Por supuesto, tenemos que partir de una constatación. La existencia de un pacto o acuerdo no es un rasgo indispensable para el desarrollo de un proceso de transición. Sin embargo, su existencia determina en sí misma las condiciones bajo las cuales dicho proceso se realiza. Es mucho menos frecuente, por no decir casi imposible, que un pacto o acuerdo para el cambio político se de en los casos 
de transiciones montadas sobre el esquema del "reemplazo" o la "trasformación". En general, pues, lo que la teoría politológica coincide en señalarnos es que cuando es viable alcanzar un pacto o acuerdo la transformación de un régimen político puede lograrse de una manera gradual, pausada y ordenada durante su instauración y enfrenta, por lo mismo, mejores perspectivas en su etapa de consolidación. Tal y como, en efecto, ocurre en los casos de transición por "traspaso".

Ahora bien, la razón de ello estriba en que el pacto o acuerdo facilita que un determinado régimen modifique su estructura institucional neutralizando el peligro de una confrontación violenta $y$, asimismo, sin que (en una condición de desequilibrio de fuerzas, necesariamente) predomine un grupo de poder sobre otro. Como nos ilustran, en este sentido, O'Donnell y Schmitter:

"La democratización avanza como un "plan en cuotas", a medida que los actores colectivos, cada uno de los cuales con una modalidad de gobierno o configuración institucional preferida, entran en una serie de compromisos más o menos permanentes. Ningún grupo social o político es lo suficientemente predominante como para imponer a los otros su "proyecto ideal", y típicamente el resultado de esto es una "segunda alternativa" con la que ninguno de los actores se identifica por completo y que no es la que ninguno de ellos anhela, pero en torno de la cual todos concuerdan y participan" ... (Y, más adelante recalcan) "El marco general para la negociación de un pacto resulta bastante claro: se trata de una situación en la que existen grupos rivales o antagónicos interdependientes, y en la que ninguno de ellos puede prescindir del otro ni imponer de manera unilateral su solución predilecta si pretenden satisfacer sus respectivos intereses divergentes"65.

Las transiciones desde el autoritarismo a la democracia en la América Latina contemporánea no se realizaron bajo la egida de un pacto político formal66. La única excepción al respecto lo fue el caso uruguayo, que si bien logro concertar un acuerdo (conocido como el pacto del Club Naval) en la práctica nunca llegó a entrar en vigor. Es decir, tal pacto llegó a ser formulado pero no llegó a ser instrumentado. Las causas que explican esta incapacidad para articular acuerdos y consensos básicos entre las distintas fuerzas políticas involucradas en un proceso de transición democrática tienen que ver directamente con la naturaleza particular de la sociedad civil y del sistema de partidos integrantes del régimen político en transición. Es decir, dependen de el grado de organización social (fuerte o débil) y desempeño partidista (activo o inactivo) de las fuerzas políticas constitutivas del régimen en cuestión.

\subsection{La determinación desfavorable del contexto internacional}

No nos detendremos mucho en el presente punto. Únicamente queremos reafirmar la argumentación general que sostiene que los factores internacionales 
son más favorables al desarrollo y consolidación de la democracia en las naciones del Sur de Europa que en los países Latinoamericanos67. En el punto 3.2 del presente artículo ya hemos señalado que las "diferencias y contrastes entre los casos (considerados) sustentan una evaluación más optimista en cuanto a las perspectivas de la instalación democrática en la Europa meridional que en América Latina"68.

Las razones de ello tienen que ver con diversos factores entre los que destaca el papel adoptado por las potencias en el escenario internacional69. El componente geoestratégico, ciertamente, juega un papel primordial en la configuración de las condiciones que hacen más viable la influencia democratizadora en un caso y otro. Es decir, tanto la distancia física como la defensa de intereses considerados como estratégicos por parte de una potencia hegemónica determinan, normalmente, su política exterior a favor o no de la promoción de la democracia. En el caso de América Latina no puede dejar de tomarse en cuenta el rol desempeñado en este sentido por Estados Unidos.

En efecto, Estados Unidos siempre a considerado a América Latina como parte de su área de influencia más cercana y donde menos tolera la influencia de otras potencias hegemónicas que no comparten su ideología liberal. Por supuesto, el discurso de las sucesivas administraciones norteamericanas ha manejado un nivel elevado de retórica a favor de la democracia que, en la práctica, ha enmascarado su apoyo a gobiernos y prácticas de claro corte autoritario. Se trata de un hecho que al parecer a nadie sorprende. Las abstractas declaraciones oficiales en favor de la democracia, en efecto, han guardado por lo general escasa correlación con las decisiones, políticas y el comportamiento observable de los funcionarios norteamericanos a la hora de defender sus intereses concretos y sus relaciones estrechas con los grupos de poder locales 70 .

Por otra parte, la escasa correlación entre discurso y práctica política en cuestión se reduce si tomamos en cuenta que los pronunciamientos norteamericanos a favor de la democracia se refieren virtualmente al modelo de democracia política. Es decir, se trata de un discurso que pone el acento, como sabemos, en las cuestiones de procedimiento y de forma (contienda electoral limpia, partidos políticos libremente instituidos, garantías a la libertad individual, etc.) a diferencia de aquella otra concepción de democracia que coloca más énfasis en su dimensión social (derechos sociales e igualdad económica, mecanismos de apropiación y distribución de la riqueza, etc.). Bajo tal lógica, se comprende cómo y porque Estados Unidos ha tolerado y alentado regímenes autoritarios a todo lo largo y ancho de América Latina que, en su particular percepción, eran más apropiados para defender la propiedad privada y combatir al comunismo ${ }^{71}$. Sin embargo, como nos recuerda G. O'Donnell "en la mayor parte de la Latinoamérica contemporánea se han producido algunos importante cambios subjetivos que, aún en medio de una árida configuración de factores "objetivos", 
ofrecen una nueva base para la esperanza acerca de la democratización".

\subsection{El alto grado de militarización y el carácter represivo del régimen}

El punto de partida del análisis del rol desempeñado por las fuerzas armadas en las estructuras de poder de las naciones latinoamericanas tiene que ver, como es fácil y objetivamente aceptado, con la extensión, profundidad y complejidad de dicho rol. No puede negarse, en efecto, que los militares han tenido una presencia permanente en la historia latinoamericana, al menos desde la formación de las repúblicas independientes en al siglo XIX72. De tal suerte, a lo largo del siglo XX, su incidencia ha sido incontrovertidamente decisiva en la configuración de la vida política e institucional de cada uno de los países del continente. En buena medida, los estados latinoamericanos — por lo menos hasta fines de los ochenta- se configuraron al amparo del poder castrense, cuyo influjo se hizo sentir con mayor fuerza hacia mediados de los sesenta, cuando se inauguraron los regímenes burocrático-autoritarios.

Por supuesto, el anterior tipo de régimen político no es el único que subsume la presencia de los militares al frente y en el control del aparato estatal. Es decir, el régimen burocrático-autoritario es, sin duda, el tipo más articulado de régimen militar, pero, como sabemos, en América Latina también se han moldeado otros tipos de éste, quizás incluso más clásicos, como los regímenes sultanistas o tradicionales (en donde los militares circunscriben su rol al de mera guardia pretoriana) y sin olvidar los militarismos populistas (más interesantes desde su clara y característica orientación antioligarquica)73.

Existen, sin embargo, dos rasgos comunes -si bien experimentados con distintos énfasis- en los distintos tipos de militarismos latinoamericanos antes de que se sucedieran las transiciones hacia la democracia en los años ochenta. En primer lugar su afán por desempeñar un papel central en la definición y el manejo de las políticas económicas. Aquí, está demás recordar que esa visión mesianica de ser los promotores del desarrollo latinoamericanos llevó a los militares a cosechar importantes fracasos. En segundo lugar, la misión de defensa, también asumida mesianicamente, de la seguridad nacional en un mundo polarizado por la guerra fría. Los dolorosos excesos a los que llevó la ejecución de la guerra contrainsurgente por el estamento castrense en América Latina son también ampliamente conocidos y documentados 74 .

En su lucha contra el avance del "comunismo", ciertamente, los militares latinoamericanos no sólo desaparecieron, torturaron y asesinaron a cientos de miles de opositores políticos, sino que prohibieron la existencia de sindicatos y partidos políticos, clausuraron parlamentos y violentaron a su antojo las constituciones políticas. En una palabra, no sólo quebraron las estructuras de la sociedad civil, sino que también rompieron las estructuras democráticas consolidadas antes del advenimiento de las dictaduras militares. El "orden" fue alcanzado y/o 
reestablecido al precio de desmembrar la sociedad civil y destruir la democracia75. Claro que esta participación decidida y directa en la guerra sucia, en la destrucción de las instituciones representativas y en el fracaso desastroso de la administración de la economía sumergió, a la larga, a las fuerzas armadas latinoamericanas en un desprestigio y deslegitimación - y en algunos casos, como el argentino, en un colapso institucional- sin precedentes.

Pero incluso en los casos de colapso institucional, los ejércitos latinoamericanos han guardado la capacidad de mantener una elevada dosis de poder, autonomía e influencia política. De ahí tenemos que tanto por su tradición como por su desempeño reciente el peso específico de los militares ha sido determinante en el desarrollo de los procesos de transición hacia la democracia. De hecho, una lección que nos arrojan las experiencias de transición democrática en Sur América es que un alto grado de militarización del régimen autoritario incrementa las dificultades de la transición, sobre todo en la etapa de la instauración pero también en el período de la consolidación76.

En realidad, el problema crucial de someter a la institución castrense al control civil y limitarles su influencia en el conjunto de la sociedad exige, en primer lugar, encontrar un fórmula creativa para reducir el poder y los amplios privilegios del estamento militar77. En segundo lugar, la construcción de un nuevo esquema de relaciones cívico-militares que haga énfasis en la profesionalización de dicho estamento, asignándoles funciones claras y limitadas y reforzando el aspecto apolítico de su ética profesional78. Y, en tercer lugar, también una fórmula para "saldar las cuentas del pasado sin desbaratar la transición presente". Es decir, el de como manejar el sensible y espinoso asunto del ajuste de cuentas con los responsables involucrados en graves hechos de violación a los derechos humanos. Conseguir tales objetivos, por supuesto, es una empresa compleja y desafiante e involucra, entre otros factores, el grado de fuerza y la habilidad negociadora por el liderazgo civil así como el grado de penetración alcanzado por los militares en la configuración del régimen autoritario sometido a la transformación democrática79.

\subsection{Sociedad civil débil y polarizado sistema de partidos}

Finalmente, en la sección presente comentaremos las características adoptadas por el desempeño de la sociedad civil en la creación y canalización de las presiones sociales que contribuyen y/o conducen a la supresión de un régimen autoritario. Como ya explicamos, el principio teórico puesto en juego aquí sostiene que el cambio político puede ser provocado por acciones colectivas de protesta tales como huelgas y otros tipos de acción propios de las organizaciones populares. Naturalmente, la intensidad de dichos actos por sí sola no provoca ni la caída de un régimen autoritario ni la transición a la democracia. Estos desenlaces particulares dependen tanto de la influencia de otros factores (internos y 
externos) involucrados como del nivel de organización alcanzado por las fuerzas sociales que retiran su apoyo al régimen sometido a las presiones de cambio80.

Ahora bien, en los casos de América Latina, una nota propia de los períodos de movilización de las masas suscitados en los momentos de crisis autoritaria ha sido su menor nivel de organización y su mayor expresión de espontaneidad. De ahí que, aunque en algunos casos como el argentino, las acciones de presión y protestas populares hayan provocado niveles de desequilibrio sistémico que contribuyeron decisivamente al colapso del régimen, la norma general en la región muestra menor organización y autonomía en el desempeño de la sociedad civil, lo cual, por lo demás, deja más espacio entre las élites gobernantes a la aplicación de estrategias liberalizadoras. Brasil constituye, en este sentido, un caso ejemplar de la debilidad mostrada por los sectores populares organizados en el desarrollo de una extraordinariamente prolongada transición hacia la democracia. En este caso, la etapa previa de liberalización mostró un alto grado de control por parte de los militares a la cabeza del régimen en la apertura controlada que llevo a la democracia81.

Muy vinculada a la existencia de una sociedad civil poco organizada se encuentra la configuración de un sistema de partidos polarizados82. En los casos de América Latina esta característica se explica por la inexistencia de los pactos que regulan la transición. Al no contar, en efecto, con un acuerdo que garantice la protección de ciertos intereses estratégicos de los principales grupos o actores sociales, la competencia por el control de los principales órganos de decisión se vuelve más intensa y los niveles de confrontación se elevan y se vuelven más abiertos. Tal panorama se hace aún más complejo por el surgimiento de fuertes oposiciones desleales que socaban los esfuerzos de los conductores de la transición ${ }^{83}$.

El cuadro No. 2 ofrece una visión sintética de los principales rasgos que configuran al modelo de transición política por colapso.

\section{A modo de conclusión: el modelo conflictivo-consensuado}

Un acertado intento de interpretación del proceso de cambio político vivido por la sociedad salvadoreña en el período de 1992 a 1995 y, que logre ir más allá de la mera descripción fenoménica del mismo, descubrirá que existe en él un inherente e interesante patrón de desarrollo. Al estudiar comparativamente el curso de otros procesos de cambıo político de similar naturaleza en otras regiones del mundo, en efecto, se puede distinguir claramente como la ruta seguida por la transición salvadoreña se apegó a un modelo intermedio de cambio político que posee rasgos compartidos tanto por los procesos de transición democrática ocurridos en el Sur de Europa (traspasos) como por los de Sur América (reemplazos y transformaciones). Un caso de transición política, pues, que a falta de una mejor definición conceptual podemos llamar de "ruptura-pactada". 


\section{Cuadro No. 2. \\ América Latina: Transiciones conflictivas}

Variables Desempeño

Transición

* Colapso del régimen (Conflictiva)

* Inexistencia de un pacto político entre los principales actores sociopolíticos (en algunos casos se da pero de manera implícita)

\begin{tabular}{lll} 
Fuerzas Armadas & $* \begin{array}{l}\text { Rol protagónico } \\
\text { Mayor o responsabilidad directa en los ac- } \\
\end{array}$ & $\begin{array}{l}\text { tos (masivos) de violencia oficial } \\
\text { Sociedad Civil }\end{array}$ \\
& $* \begin{array}{l}\text { Débil } \\
\text { Polarización partidaria } \\
\text { Existencia de oposición desleal (antiré- } \\
\text { gimen) }\end{array}$ \\
\hline Contexto Internacional & $*$ & Desfavorable \\
\hline Tipo de régimen & $*$ & Mayor grado de militarización \\
& $*$ & $\begin{array}{l}\text { Burocrático autoritario, Sultanista o Tra- } \\
\text { dicional y Populismos }\end{array}$ \\
& &
\end{tabular}

\subsection{Una transición cuidadosamente pactada}

De esta suerte, en El Salvador, al igual que en las naciones de la Europa del Sur, la transición democrática se rigió por un acuerdo o pacto político que estableció de manera ordenada los procedimiento institucionales que regularon el curso de la transición y establecieron su metas y objetivos a alcanzar. Sin embargo, el pacto gestado en el caso salvadoreño se diferencia de los pactos gestados en la Europa mediterránea por su carácter elitista más propio de los negociaciones discrecionales e informales que se dieron entre los sectores "blandos" de las élites empresariales y militares ante el desmenbramiento de la sociedad civil, provocado por los regímenes burocrático autoritarios en el Cono Sur. La falta de la participación y/o representación directa de todos los actores sociopolíticos fundamentales (empresarios, militares, sindicalistas, políticos profesionales, etc.) en la configuración del Acuerdo de Chapultepec colocaría al mismo a medio camino entre el pacto explícito y representativo para normar la transición de la Europa mediterránea y la ausençia del mismo en el Cono Sur. 


\subsection{Una sociedad civil débil acompañada de una fuerte oposición antisistémica}

En segundo lugar, y muy relacionado con el anterior punto, el desempeño de la sociedad civil en las presiones sobre la coalición dominante para inducir y/o forzar la transición hacia la democracia desempeño un papel destacado de primera importancia en las naciones de la Europa mediterránea. En cambio, en las transiciones de Sur América el rol desempeñado por la sociedad civil fue más bien débil y las causas que explican la ruptura o colapso del régimen autoritario obedecen más bien a factores de otra naturaleza como, por ejemplo, una severa crisis de legitimidad o una pérdida del equilibrio sistémico al interior mismo de la coalición dominante. En el caso salvadoreño nos encontramos de nuevo frente a una postura intermedia. El rol desempeñado por la sociedad civil es débil aunque la presión sobre el régimen autoritario es radicalmente antisistémica al extremo de llegar a la oposición armada. Sin embargo, en el caso salvadoreño, tampoco se trata de una transición por colapso propias de las transiciones en Sur América como ya vimos sino que surge de un acuerdo negociado explícito, construido para tal fin por parte de las cúpulas de las fuerzas en confrontación.

Otro aspecto estrechamente vinculado al anterior, aunque más propio de la sociedad política que de la sociedad civil, es el que se refiere al rol jugado por los organismo políticos de intermediación en el curso de la instauración y la consolidación posterior de la democracia. En la Europa mediterránea, en efecto, los partidos de centro predominaron contundentemente en los resultados de las elecciones fundacionales y contribuyeron, en este sentido, a crear un evidente y propicio clima de despolarización social. En el extremo opuesto, en las transiciones Sudamericanas, los partidos de derecha predominaron como norma y la polarización social llegó al extremo de manifestar la presencia de una oposición desleal y conflictiva. El patrón seguido en el caso salvadoreño es, en este punto, muy parecido a los casos latinoamericanos referidos aunque la polarización y el predominio de la derecha en los comicios fundacionales no dio paso a la expresión de la oposición desleal.

\subsection{El repligue parcial de las Fuerzas Armadas y el limitado castigo a los responsables de las violaciones a los derechos humanos}

En tercer lugar, tenemos como factor fundamental del proceso de cambio político, el examen del rol jugado por las fuerzas armadas en el curso del mismo. Y, aquí no cabe duda de que una de las causas que explican la mayor estabilidad y homogeneidad en la etapa de instauración democrática de la Europa mediterránea estriba en el rol modesto desempeñado por los militares en la organización y vigencia del régimen autoritario así como la ausencia de responsabilidad directa (o bien, la mayor distancia en el tiempo existente) en los actos de violencia oficial ejercida por estos regímenes. En cambio, en Sur América, la 
responsabilidad directa e institucional del estamento castrense en los graves actos de violación a los derechos humanos y las legítimas muestras de reparación exigidas por las víctimas de tal violencia o sus familiares fue uno de los principales factores que empañaron y amenazaron la estabilidad del proceso de transición. El caso salvadoreño está, una vez más, muy cerca del modelo latinoamericano descrito. Sin embargo, en El Salvador, a pesar de que una Comisión de la Verdad examinó y dictaminó sobre la responsabilidad de más de 22,000 casos graves de represión, asesinatos y violencia ocurridos durante los 12 años de duración del conflicto, ello no llevó a ningún alto oficial a ser enjuiciado y/o condenado por su participación y responsabilidad en la ejecución de esa violencia oficial extrema.

\subsection{Un contexto internacional relativamente favorable}

En cuarto y último lugar comentaremos la influencia del contexto internacional en la creación de un clima propicio para la transición democrática. En la Europa mediterránea la influencia internacional constituyó un poderoso estimulo para dar paso a democracias políticas que contaban con la extraordinaria ventaja de instaurarse en naciones con un nivel de desarrollo más elevado o potencialmente más factible de alcanzar en el corto plazo. En Sudamérica, el panorama fue, en realidad, el opuesto. Además, la dificultad hasta la fecha insalvable de avanzar en el terreno de la democracia económica en dichas naciones ha contaminado y/o contribuido también a la emergencia de democracias políticas frágiles y débiles. En El Salvador, por su parte, el desafío de la democracia económica o la necesidad de disminuir la amplia brecha en la distribución del ingreso y la riqueza nacional sólo permiten hacer vaticinios negativos acerca del futuro de la consolidación democrática. No obstante lo anterior, la influencia de factores exógenos en el desencadenamiento y posterior curso de la instauración democrática habla por sí sólo de la existencia de un contexto internacional favorable para arribar a la democracia política.

\section{Notas:}

1. Investigador del Centro de Información, documentación y apoyo a la investigación (CIDAI)

2. El presente artículo es una versión brevemente resumida y modificada del primer capítulo de la tesis: El Salvador: Una transición democrática de baja intensidad (1992-1995) que para optar al grado de Maestro en Ciencia Política el autor presentó a la División de Estudios de Posgrado de la Facultad de Ciencias Políticas y Sociales de la Universidad Nacional Autónoma de México (UNAM).

3. A. Sermeño, "El Salvador: democracia de baja intensidad", ECA, 1995, 558: pp. 379-380.

4. Cabe destacar que: "la política comparada no constituye sólo un sector de la ciencia política con métodos, objetos de análisis y autores de referencia propios; asimismo -y tal vez sobre todo- es un modo de investigar el conjunto de fenómenos políticos, 
una manera de profundizar en el análisis empírico y en la teoría política en todos los sectores del conocimiento". (Cfr. B. Badie, G. Hermet, Política comparada, México, D.F. Fondo de Cultura Económica, 1993, p. 7.

5. En este sentido concordamos con César Cansino para quien: "no obstante las limitaciones que aún pesan sobre este campo de investigación en términos tanto de su alcance teórico, todavía descriptivo y probabilístico, como del tipo de generalizaciones que puede lograr mediante la aplicación del método comparativo, constituye un campo de reflexión que en poco tiempo ha aportado importantes conocimientos sistemáticos sobre los procesos de cambio y adaptación de los sistemas políticos". (Cfr. C. Cansino, México una transición inconclusa 1977-1994, México, D.F, Fondo de Cultura Económica/Centro de Investigación y Docencia Económica (CIDE), en prensa.

6. La siguiente sección del presente apartado se encuentra inspirada y documentada en "crisis autoritaria y liberalización política: el esquema teórico" que es el capítulo primero de uno de los recientes libros de César Cansino. Cfr. C. Cansino, México: Una transición inconclusa 1977-1994, México, FCE/CIDE, 1995.

7. Esta perspectiva explica los procesos de cambio político dando una importancia central al análisis del comportamiento de los actores políticos (partidos políticos, grupos de interés, movimientos sociales, representantes del poder, protagonistas del cambio, etc). Los actores, en esta perspectiva, configuran sus relaciones políticas a partir de sus intenciones e intereses (estrategias, cálculos y decisiones). Ello no supone, sin embargo, que ésta perspectiva de investigación excluya a priori aquellos condicionamientos de tipo económico, cultural, internacional, etc. Es decir, condicionamientos, como sabemos, de carácter estructural. Cfr. J. Linz, La quiebra de las democracias, México, CONACYT/Alianza, 1990.

8. D. Easton, Enfoques para el análisis sistémico de la política, Buenos Aires, Amorrortu, 1980.

9. Cfr. J. Linz, "Totalitarian and Authoritarian Regimes", en F. Greestein y N. Polsby (eds.), Handbook of Political Sciencia, Reading, Massachusetts, 1975., t. 3, pp. 264-267.

10. L. Morlino, "La transición de régimen" en C. Cansino (comp.) Las teorías del cambio político, México, Universidad Iberoamericana, 1993, vol. 1., pags. 163-180.

11. G.A. Almond y G.B. Powell, Política comparada: una concepción evolutiva, Buenos Aires, Paidós, 1972.

12. La concepción de crisis política que manejamos "parte de considerar a los regímenes políticos y sus procesos de cambio y adaptación. En este sentido, tal y como hemos desarrollado, la crisis política se concibe como un proceso de desequilibrio interno y desestabilización que acontece en un régimen de pluralismo limitado y no responsable. La situación crítica que puede impulsar a una transformación del régimen puede ocurrir cuando la capacidad de éste de liderar con problemas internos o sistémicos disminuye, propiciando precisamente un estado de equilibrio inestable o abierto desequilibrio". Cfr. C. Cansino, México una... op. cit.

13. "Entre los indicadores más importantes para el análisis empírico de la crisis autoritaria destacan los siguientes: tipo y número de cleavages o líneas de conflicto existentes en la sociedad y que se transfieren a la esfera política; actores y recursos políticos en el seno de la coalición dominante y sus conflictos, acuerdos, estrategias y tensiones internas". Cfr. op. cit. 
14. Cabe destacar que otros polítologos consideran un mayor número de opciones posibles de desenlace en una situación de crisis política (y más propiamente de crisis autoritaria). Así para Juan Antonio Crespo los posibles desenlaces de una situación de crisis política son los siguiente: "a) el regreso al juego habitual, que se conoce como "restauración" o "reequilibrio" del régimen vigente, b) la aceptación de nuevas reglas más equitativas, lo que se denomina como una "democratización", c) el fin del juego, a través de la fuerza de las condiciones de los antiguos gobernantes, lo que se designa como "involución política", es decir, el retorno a fórmulas represivas que habían quedado más o menos superadas, y d) la confrontación entre los actores políticos, dando lugar al fin del juego por vías de la inestabilidad, la ingobernabilidad y, probablemente, la violencia, escenario en el cual podría salir airosa la oposición (lo que sería un derrocamiento), o se prodría llegar finalmente a un acuerdo entre ambas partes, si ninguna logra imponerse sobre la otra, lo que daría lugar a un acuerdo forzado a la democracia, que tendría mayor fragilidad que en caso de lograrse por la vía pacífica". Cfr. J.A. Crespo, "La transición entrampada", Enfoque, semanario político del períodico Reforma, No. 38, 28 de agosto de 1994, p. 12.

15. "El paso de un régimen -nos dice Leonardo Morlino- a otro comporta siempre un cambio fundamental: el nuevo régimen se presenta en algunos o en todos sus aspectos eseciales como diverso del anterior. Así defino en síntesis la transición de régimen: un cambio fundamental que comporta siempre el paso de un régimen a otro cuyas características esenciales son palmariamente diversas". Cfr. L. Morlino. "La transición de régimen", en C. Cansino (comp.) Las teorias del cambio político... op. cit. p. 175.

16. L. Morlino. "La transición de.. op. cit. p. 175.

17. "La mayor capacidad de cambio-adpatación -nos dice Morlino-, aunque sea con pasos pequeños y graduales, del régimen democrático respecto al regimen autoritario, debe destacarse explícitamente. El régimen autoritario no siempre Ilega a sobrevivir a la desaparición del lider o del grupo gobernante. Más bien el momento de la sucesión o de la sustitución de autoridad es uno de los momentos más difíciles y delicados de este tipo de régimen, el momento en que sale a luz su inferior capacidad de adaptación". Cfr. L. Morlino. op. cit. p. 176.

18. Cp. cit. p. 177.

19. Cfr. C. Cansino... op. cit. Véase también: G. O'Donnell, P. Schmitter y L. Whitehead, Transiciones desde el autoritarismo a la democracia, vol. 4, Conclusiones tentativas acerca de democracias inciertas, Buenos Aires, Paidós, 1988.

20. César Cansino sostiene que "las estructuras de autoridad de un régimen autoritario pueden iniciar un proceso de liberalización política cuando el nivel de legitimidad hacia el régimen muestra una tendencia decreciente y cuando la movilización conflictiva muestra una tendencia creciente". op. cit.

21. "Para distinguir empíricamente entre un proceso de liberalización y uno de democratización habrán de considerarse cuando menos los siguientes indicadores: a) el grado de impredecibilidad que genera su implementación a nivel decisional (mientras que la democratización abre mayores márgenes de impredecibilidad por cuanto las decisiones políticas involucran una diversidad de actores y proyectos a veces contradictorios, la liberalización reduce tales márgenes al mínimo por cuanto la toma de decisiones sigue estando monopolizada por una élite política reconocida); b) las modificaciones institucionales que produce a través de reformas electorales, cambios 
constitucionales sustanciales y demás garantías política y civiles (mientras que la democratización da lugar a un arreglo institucional, normas y valores reconocidamente democráticos, las reformas producto de una liberalización siguen presentando ambiguedades y parcialidades); c) evidencia o no de acuerdos o negociaciones entre actores políticos identificados con el régimen autoritario precedente y actores en menor o mayor medida antirégimen; y d) el nivel de pluralismo político permitido". lbidem.

22. op. cit.

23. R. Dahl, La Poliarquía. Participación y oposición, México, REI, 1993.

24. op. cit.

25. Cabe destacar, sin embargo, que la idea de democracia es sumamente compleja y su definición y desarrollo se encuentra marcado por concepciones contrapuestas. En realidad, no existe una respuesta simple a la pregunta de ¿qué es la democracia? En el intento de responderla, de hecho, es cuando hacen su aparición los innumerables adjetivos que si bien sirven para mostrar la complejidad del citado fenómeno introducen al final de cuentas mayor confusión y oscuridad para su adecuada comprensión.

26. A. Przeworski, "Algunos problemas en el estudio de la transición hacia la democracia", en: G. O'Donnell, P. Schmitter y L. Whitehead (comp.) Transiciones desde un gobierno autoritario/ 3. Perspectivas comparadas, Buenos Aires, Paidós, 1994, pp. 79-104.

27. "Institucionalización -ha definido de forma ya clásica S.P. Huntington- es aquel proceso por el cual organizaciones y procedimientos conquistan valor y estabilidad. Los niveles de institucionalización de cualquier sistema político pueden definirse por la adaptabilidad, la complejidad, la autonomía y la coherencia de sus organizaciones y procedimientos. Asimismo, el nivel de institucionalización de cualquier organización política o procedimiento puede medirse por su adaptabilidad, su complejidad, su autonomía y su coherencia. Si estos criterios pueden identificarse y medirse, los sistemas políticos pueden comparse en términos de sus niveles de institucionalización. Y será posible también medir incrementos y descensos en la institucionalización de particulares organizaciones y procedimientos en el interior de un sistema político". Cfr. S. P. Huntington. El orden político en las sociedades en cambio, Buenos Aires, Paidós, 1990 (reimpresión), pp. 18-19. También puede consultarse: C. Cansino. "La teoría de la institucionalización política de Huntington. (a veinte años de Political Order in Changing Societies)", en Estudios Políticos, México, No. 6. abril-junio, 1991, pp. 23-33.

28. Cfr. L. Morlino. "Las instauraciones democráticas en Europa Mediterránea", en C. Huneeus (comp.), Para vivir la democracia. Dilemas de su consolidación, Santiago, Avante, 1987, pp. 223-256.

29. Tras la caída del muro de Berlin hasta la fecha hemos presenciado un nuevo proceso global de transición política. Se trata del paso del comunismo a la democracia en la Europa central -las llamadas "revoluciones de terciopelo" en clara referencia a la desintegración checoslovaca. En rigor dicho fenómeno podría y de hecho ha de ser suceptible de ser caracterizado a través de su propio modelo analítico explicativo. En la presente investigación, no obstante, por simples razones de delimitación no lo tomanos en consideración, ni estudio. Cfr. M. Cotta. "Transitions to Democracy and the Building of New Party Systems. The East European Cases in Comparative 
Perspective", Paper presented at the Join Sessions of Workshops of the European Consotium for political Research -University of Essex 22-28 March 1991. F. Mires. El orden del caos. ¿Existe el Tercer Mundo? Caracas, Nueva Sociedad, 1995.

30. G. Sartori. La Política. Lógica y método en las ciencias sociales, México, FCE, 1992.

31. "En este rubro se incluyen interrogantes sobre el tipo de régimen autoritario en cuestión, el tipo de tradición política en el país, el tipo de experiencia política exhibida (antecedentes o no de comportamiento democrático); las prácticas de dominación autoritaria (las reglas escritas y no escritas del juego político); la medida en que se ha institucionalizado el régimen y, ante todo, la medida en que se han iniciado y tolerado formas de participación de la población, de grupos sociales y fuerzas políticas; formas de exclusividad-inclusividad promovidas y/o permitidas; tipo de políticas socioeconómicas seguidas; características de los subsistemas partidistas, electoral y parlamentario consentidos por el régimen". Cfr. C. Casino., op. cit.

32. En este rubro habrá que distinguir entre los factores externos, los internos del régimen y aquellos concernientes a la oposición. Entre los primeros debe considerarse la existencia o no de presión continua de poderes extranjeros sobre el régimen autoritario para influir en ciertos desenlaces. Entre los internos deberán individualizarse los distintos actores políticos, así como sus estructuras y modelos de comportamiento, sus recursos políticos y conflictos internos. Deberán considerarse también los grupos de influencia que apoyan al régimen y sus formas de interacción y presión. Un factor adicional que habrá que considerar es el tipo de repercusiones sociales y políticas que tienen lugar como resultado de las transformaciones de la estructura económica y social". Cfr. C. Cansino., op. cit.

33. Para mayor claridad véase la definición de transición política arriba esbozada. No está de más recordar que la continuidad/discontinuidad, el grado de velocidad, el nivel de conflictividad y la predominancia del factor interno/externo manifestados por los procesos de transición democrática dependen en cada caso particular de la combinación de los factores de largo y corto plazo (ver notas 28 y 29) específicos en la configuración de cada proceso de cambio político.

34. S.P. Huntington, La tercera ola, Buenos Aires, Paidós, 1994.

35. J.A. Crespo, "La transición inconclusa", ... op. cit.

36. España, Portugal y Grecia son la naciones del sur de Europa que transitaron a la democracia en la década de los setenta. Italia y Francia sufrieron la misma experiencia a fines de los años cuarenta. Algunos expertos en política comparada, haciendo las debidas excepciones y consideraciones, estudian los cinco casos de forma simultanea. Turquía, un caso todavía más atípico que los anteriores también suele ser considerado por los politólogos comparatistas dentro de la categoría de naciones mediterráneas que han transitado a la democracia bajo un esquema de desarrollo similar.

37. "Cuando el equilibrio es claro para las distintas fuerzas en pugna, el acuerdo para la transición se facilita enormemente y casi con seguridad puede alcanzarse, aunque ello depende a su vez de que los moderados de ambas partes predominen en sus respectivos partidos y organizaciones". Cfr. J.A. Crespo, "La transición entrampada"... op. cit.

38. Nos referimos al hecho de que en una transición pactada es más viable dar paso a un régimen político construido sobre esquemas que privilegian un comportamiento poli- 
tico democrático donde predominan valores positivos tales como la participación, la persuasión y la representación por encima de otros valores negativos (propios de los autoritarismos) como la exclusión, la coerción y el orden.

39. "La transición desde el autoritarismo a la democracia se produjo en España, no por la vía de una ruptura radical con el régimen anterior, ni a través de un proceso de autotransformación del régimen mismo. Se trató más bien del producto de una serie de pactos y negociaciones en los cuales fueron protagonistas claves varios actores políticos. Las expresiones "ruptura pactada" y "reforma pactada" expresan esta ambiguedad. La primera subraya la falta de continuidad política entre los dos tipos de régimen y los principios de la legitimación que les daba sustento, y la segunda pone énfasis en el elemento de continuidad legal a través del cual fue puesto en práctica el cambio, con alto grado de respeto formal por la legalidad del sistema político de Franco. En todo caso, ambas fórmulas hacen hincapié en la importancia que tuvo el acuerdo, el consentimiento o la concertación durante la operación política que permitió el reemplazo de un régimen por otro". Cfr. J.M. Maravall y J. Santamaría, op. cit. p. 115-116.

40. La transición política española comenzo en 1976 , con la renuncia de Carlos Arias Navarro a petición del Rey, y la incorporación de Adolfo Suárez como presidente para que generaran los acuerdos necesarios entre las diversas fuerzas políticas. Suárez concibió la transición como un pacto entre fuerzas, en el que supo aprovechar la legalidad franquista para Ilegar a una legalidad democrática en 1978, fecha en la que, con la aprobación de la Constitución vigente hoy, España entra en la democracia a secas. Cfr. Enrique Zuleta Puceiro, "Transición política y estrategias institucionales, en E. Baylora, E. Catterberg y otros, Lecciones para demócratas en transición. Buenos Aires, Ed. Belgrano, 1987, p. 99-162. N. Caballer, "Transición española" (entrevista con Alberto Begne), Enfoque, No. 38, 28 de agosto de 1994, p. 17.

41. El esquema de construcción del modelo de transición pactada a la democracia lo tomamos, introduciendo ligeras variantes de: Philippe Schmitter, "Una introducción a las transiciones desde la dominación autoritaria en Europa meridional: Italia, Grecia, Portugal, España y Turquía”, en G. O’Donnell, P.C. Schmitter y L. Whitehead, Transiciones desde un gobierno autoritario. Vol. 1, Perspectivas comparadas, Buenos Aires, Paidós, 1994 (primera reimpresión).

42. En el caso español, por citar el ejemplo más ilustrativo, el autoritarismo Fraquista había durado cuarenta años. En Portugal, igualmente, el gobierno autoritario consolidado duro tanto tiempo que toda una generación o más se desarrollaron sin ninguna experiencia directa de los derechos o procesos democráticos.

43. Para Morlino es la interacción de tres factores, entre los que se encuentra la duración del régimen autoritario, lo que explica los tiempos (el grado de rápidez) y los modos (lineal y homogenea o discontinua) de la transición y de la instauración. Los otros dos factores son la precedente experiencia democrática y el grado de participación y/ o movilización de los grupos opositiores tolerada por el régimen autoritario mientras se mantenía firme y estable. Cfr. L. Morlino, "Las instauraciones democráticas en Europa mediterránea. Algunas hipótesis comparativas", en E. Baylora, E. Catterberg y otros; Lecciones para demócratas en transición, Buenos Aíres, Ed. Belgrano, 1987, p. 243.

44. Cfr. José María Maravall y Julian Santamaría, "El cambio político en España y las perspectivas de la democracia", en P.C.Schmitter, G.O'Donnell y L. Whitehead, op. cit. 
45. P.C. Schmitter, "Una introducción a las.... op. cit. p. 17.

46. op. cit.

47. Cfr. P. González Casanova, Los militares y la política en América Latina, México, 1988, p. 17. L.A. González, "Los militares latinoamericanos", ECA, 1995, 564: 1011-1016.

48. Bajo la anterior línea de argumentación entendemos por "militarismo" el fenómeno socio-político consistente en el predominio y control del estamento castrense por encima de las instituciones políticas civiles. El militarismo, en consecuencia, se caracteriza por irrumpir en la esfera del poder civil y monopolizar su ejercicio imprimiendo esquemas de acción que permean a toda la sociedad los cuales están basados en el autoritarismo, el verticalismo, la prepotencia y la impunidad.

49. G. O'Donnell, P. Schmitter, L. Whitehead, op. cit., Vol. 4. Conclusiones tentativas sobre las democracias inciertas, p. 51.

50. op. cit. Vol 1. p. 18-19.

51. op. cit. Vol. 4. p. 51.

52. P. Schmitter, "Una introducción a las transiciones... op. cit.

53. Cfr. L.A. González, "Qué es la sociedad civil y cuáles son sus desafíos fundamentales", ECA, 1995, 557: 252-256.

54. "Hay que observar que en la noción general de Estado intervienen elementos que hay que reconducir a la noción de sociedad civil (en este sentido, pudiera decirse, de que Estado = sociedad política + sociedad civil, o sea, hegemonía acorazada de coación)". Cfr. A. Gramsci, Antología, México, Siglo XXI, 1981.

55. Para que ello suceda, la movilización política tiene que presentar ciertas condiciones: debe tratarse de una movilización conflictiva y no generada desde arriba, debe haber sobrepado un umbral de intensidad tal que haya producido cambios fundamentales en las demandas políticas, en las coaliciones de apoyo al régimen y, consecuentemente, en la eficacia decisional y en la efectividad del régimen. Adicionalmente debe ser una movilización política en la cual convergen diversos sectores e intereses y que pone en juego una gran diversidad de recursos influyentes. Cfr. C. Cansino, Los conceptos y categorías del cambio político, op. cit. A. Sermeño, "Agitación sociolaboral: ¿sobrecalentamiento del sistema político?", ECA, 1995, 561-562, pp. $712-715$.

56. "La lista potencial de factores históricos parece interminable: mayor densidad poblacional, pautas más compactas de asentamiento, menor movilidad interna, guerras frecuentes, inconformismo religioso, flujos migratorios, dispersión de la propiedad de la tierra, menor estratificación etnica, mayor diversidad de idiomas y dialectos, aptitudes ocupacionales más amplimante distribuidas y especializadas, niveles más altos de alfabetización preindustrial, menor predominio de la ciudad central y mayor autonomía de las ciudades provinciales, tradiciones más profundamente enraizadas de organización gremial, etcétera”. Cfr. P. Schmitter, op. cit. p. 21.

57. op. cit. Vol. 1. p. 19.

58. L. Morlino, "Partidos políticos y consolidación democrática en el sur de Europa", en J. Benedicto y F. Reinares (eds.), Las transformaciones de lo politico, Madrid, Alianza Universidad, 1992.

59. El caso disonante de las revoluciones de tercipelo ocurridas en la Europa postcomunista en los primeros años de los noventas y que caería dentro de esta clasificación de transición por colapso sería la Rumania de Ceaucescu. 
60. Pero como ya habiamos advertido, el que nos esforcemos por describir las pautas comunes de cambio político que en general comparten estas naciones en sus respectivas zonas geográficas, ello no supone que no reconozcamos las particularizades y especificidades correspondientes a los procesos internos de cada país estudiado y/o mencionado. Por ejemplo, no cabe duda que Brasil ofrece mayores similitudes con las caracteristicas que modelan el cambio político en el Sur de Europa que con el de Sur América. De hecho, para ser más preciso, el caso brasileño más que adecuarse al modelo del "reemplazo" o al del "traspaso" correspondería al modelo de la "trasnformación". Ello, en virtud del control y flexibilidad exhibida por la élite en el poder. En efecto, a pesar de tratarse de un régimen burocrático-autoritario, en Brasil la élite gobernante se caracterizo por el predomino de los sectores "blandos", lo cual facilitó el dilatado proceso de liberalización de ese país.

61. En este tipo de transición por colapso también podrían presentarse obstáculos menos formidables a los avances en la democratización económica y social. Con todo, ello no es inexorable ni absolutamente seguro que suceda. La democratización económica y social, tal y como la entendemos en la primera parte del presente capítulo, es un proceso sumamente complejo y, al menos en el caso de América Latina, los gobernantes todavía no han ideado la fórmula o el camino acertado para su consecusión. Es decir, en la ideación de mecanismos y procesos que eliminen la acentuada, escandalosa y endemica desigualdad social característica de la región.

62 . G. O'Donnell, "Introducción a los casos latinoamericanos", en G. O'Donnell, et. al. op. cit, Vol. 2, América Latina.

63. Los casos latinoamericanos no sólo son más númerosos que los de la Europa Mediterránea. También expresan un mayor nivel de contraste y específicidad entre sí. A pesar de ello, su estudio demuestra objetivamente los rasgos comunes en los que fundamentamos el esbozo de modelo de cambio político discutido y examinado en el presente apartado.

64. "Un pacto puede definirse -nos explican O'Donnell y Schmitter- como un acuerdo explícito, aunque no siempre explicitado o justificado públicamente, entre un conjunto selecto de actores que procuran definir (o, mejor aún, redefinir) las reglas que rigen el ejercicio del poder, sobre la base de garantías mutuas concemientes a los "intereses vitales" de quienes los acuerdan". Cfr. G. O'Donnell, P. Schmitter, "Conclusiones tentativas sobre las democracias inciertas", op, cit. p. 63.

65. Cfr. op. cit. pp. 65-66.

66. En realidad únicamente Venezuela y Colombia han sido los casos latinoamericanos de democratización política cuidadosamente pactada. Sin embargo, ambos procesos tuvieron lugar en los años cincuenta y ofrecen algunas particularidades que los diferencian de los procesos de transición desencadenados en los años ochenta, sobre todo, en las latitudes del Cono Sur. Cfr. T. Lynn Karl, El petróleo y los pactos políticos: la transición a la democracia en Venezuela" en G. O'Donnell, et. al. op. cit. Vol. 2.

67. L. Whitehead, "Aspectos internacionales de la democratización", en G. O'Donnell, P. Schmitter y L. Whitehead (comp.). op. cit. Vol. 3. Perspectivas comparadas.

68. G. O'Donnell, "Introducción a los... op. cit. p. 16.

69. Para Samuel Huntington, un proceso de cambio político de grandes dimensiones y con características de alcance global como los procesos estudiados de la Europa mediterranea o en América Latina encuentran en su origen las siguientes explicacio- 
nes: Causas unicas, por ejemplo la aparición de una potencia en el escenario internacional. Desarrollo paralelo que sugiere un nivel similar de desarrollo interno de un grupo determinado de naciones. Efecto bola de nieve el cuál no es otro que el efecto de demostración o teoría del domino en donde a partir de una causa única de cambio interno dentro de una nación puede generalizarse por imitación y desencadenarse todo un proceso de cambio global con rasgos comunes. La solución que prevalece que es la existencia de una respuesta común -la democratización o el autoritarismo, por ejemplo- a diferentes desafíos o problemas dentro de distintas naciones. $\mathrm{S}$. Huntington, op. cit. p. 41-41.

70. L. Whitehead, op. cit. p. 23.

71. op. cit.

72. Louis W. Goodman sostiene al respecto: "Para los militares, los ciento setenta y cinco años desde la independencia de España estuvieron signados por la crisis del régimen civil, sin solución de continuidad, y por la continua y heroica salvación de su patria realizada por su institución". Cfr. L.W. Goodman. "Los militares y la democracia: A modo de introducción" en L.W. Goodman, J.R. Mendelson y J. Rial (comp.) Los militares y la democracia. El futuro de las relaciones cívico-militares en América Latina, Montevideo, PEITHO, 1990, p. XV. También, P. González Casanova, op. cit.

73. G. O'Donnell, "Introducción a los... op. cit. pp. 16-17.

74. En relación, pues, al anterior modelo de las naciones de la Europa mediterranea, no cabe duda, que en América Latina encontramos indices infinitamente más elevados de violencia y represión, cuya responsabilidad resulta directa e inexorablemente imputable a las fuerzas armadas de la región.

75. De nuevo de la mano de Louis Goodman podemos recordar que: “...muchos de estos regímenes civiles fueron reemplazados por un gobierno militar en los años sesenta y en los setenta. Los gobiernos militares que tomaron el poder, se caracterizaron con frecuencia por el temor al desorden social y a la subversión marxista, y por la dura represión que afectó los derechos fundamentales de buena parte de la población". Cfr. op. cit.

76. Cfr. A. Rouquié, "La desmilitarización y la institucionalización de los sistemas políticos dominados por los militares en América Latina", G. O'Donnell, P. Schmitter y L. Whitehead, op. cit. vol. 3. pp. 171-212.

77. A. Sermeño, "Militarismo, ineficiencia gubernamental y crimen organizado", ECA, 1995, No. 557, pp. 248-251.

78. S. Huntington, op. cit. G. O'Donnell y P. Schmitter, op. cit. vol. 4. pp. 50-61.

79. Como nos aseguran en este sentido, O'Donnell y Schmitter: "Nuestra conclusión es que existen posibilidades condicionadas para instar a los militares a que dejen el poder e inducirlos a tolerar una transición hacia la democracia. Entre los problemas inmediatos más difíciles de resolver se encuentran la manera de administrar justicia a los responsables directos de los pasados actos de represión, y de establecer cierto control civil sobre las decisiones relativas a la promoción y a la asignación de recursos dentro de las fuerzas armadas. Como ya hemos dicho, a largo plazo los problemas (y las esperanzas) están dirigidas a la modificación gradual de la imagen que los militares tienen de sí mismos como custodios supremos del interés nacional, logrando que abandonen su preocupación por la seguridad interior para adoptar otro papel más verosímil y ortodoxo, el de defensores de la seguridad exterior del país (o de la 
región)". G. O'Donnell, P. Schmitter, op. cit. p. 61.

80. A. Stepan, "Caminos hacia la redemocratización: consideraciones teóricas y análisis comparativos", en G. O'Donnell, P. Schmitter y L. Whitehead (comp.), op. cit. vol. 3. pp. 105-135.

81. L. Martins, "La "liberalización" del gobierno autoritario en Brasil", op. cit. vol. 2. pp. 113-146.

82. Cfr. M. Cavarozzi, M.A. Garreton, Muerte y resurrección. Los partidos políticos en el autoritarismo y las transiciones del cono sur, Flacso...

83. Tal y como argumenta Guillermo O’Donnell: "el caso de la transición por colapso del régimen es el que con mayor probabilidad conduce a un tipo más completo, menos restringido de democracia política. Podría ser también el que presenta obstáculos menos formidables a los avances en la democratización económica y social. Pero por las mismas razones (es decir, porque deja a las clases dominantes y a las fuerzas armadas con muy escasa representación en la palestra institucional de la democracia política), es también más probable que la pauta de democratización por colapso conduzca al surgimiento de fuertes oposiciones desleales y a confrontaciones directas entre partidos, facciones e intereses organizados. En consecuencia, esta pauta parece más proclive a llevar a severas reversiones autoritarias". Cfr. G. O'Donnell, op. cit. p. 23. 